\title{
EXPLORANDO OS CONDICIONANTES DA FORMAÇÃO DE REDES SOCIAIS: ESTUDO COMPARATIVO ENTRE ORGANIZAÇÃO PÚBLICA E PRIVADA
}

\section{EXPLORING THE CONDITIONS OF FORMATION OF SOCIAL NETWORKS: COMPARATIVE STUDY BETWEEN PUBLIC AND PRIVATE ORGANIZATION}

\author{
Juliana Mayumi Nishi Correio \\ Doutoranda em Administração na Universidade Federal de Santa Maria - UFSM \\ Santa Maria, RS, Brasil \\ E-mail: julianamnishi@gmail.com \\ Mauri Leodir Löbler \\ Professor Doutor em Administração do Programa de Pós-Graduação da Universidade Federal de Santa Maria \\ Santa Maria, RS, Brasil \\ E-mail: mllober@gmail.com
}

\begin{abstract}
RESUMO
A presente pesquisa objetiva verificar os condicionantes que influenciam a formação das redes sociais de informação, amizade e confiança em organizações pública e privada. Nesse sentido, o estudo de casos múltiplos é descrito como exploratório, quantitativo e qualitativo. Para o tratamento e investigação dos dados utilizaram-se os softwares Ucinet 6.0, NetDraw, NVivo e a técnica de análise de conteúdo à visão de Bardin (2006). Como resultados, notou-se que as Redes de Informação envolveram a posição hierárquica e organizacional; as Redes de Amizade foram explicadas pela a posição organizacional, proximidade física, estrutura de interações e o tempo investido na manutenção de relacionamentos; e as Redes de Confiança foram explicadas pela posição hierárquica. Os principais motivos da formação de laços nas escolas privada e pública não foram somente aspectos formais, mas também as qualidades pessoais e profissionais do indivíduo citado.
\end{abstract}

Palavras-chave: Redes Sociais. Qualidades Pessoais e Profissionais. Motivos.

\section{ABSTRACT}

This research aims to verify the conditions that influence the formation of social networks of information, friendship and trust in public and private organizations. In this sense, the multiple case study is described as exploratory, quantitative and qualitative. For the treatment and research of the data we used the Ucinet software 6.0, NetDraw, NVivo and the content analysis technique to view Bardin (2006). As a result, it was noted that the Information Networks involved the hierarchical and organizational position; the Friendship networks were explained by the organizational position, physical proximity, interactions structure and the time invested in maintaining relationships; and Confidence-Building Networks were explained by the hierarchical position. The main reasons for the formation of bonds in private and public schools were not only formal, but also the personal and professional qualities of that individual. Keywords: social networks, personal and professional qualities, reasons.

Keywords Social Networks. Personal and Professional Qualities. Reasons.

Data de aprovação: 8 de abril de 2017.

Data de submissão: 13 de outubro de 2015. 


\section{INTRODUÇÃO}

A evolução histórica das redes sociais não é recente. Ao analisar as teorias da administração, percebe-se que entre os anos de 1930 e 1970 houve um aumento no número de antropólogos, sociólogos e psicólogos na procura em construir o conceito de estrutura social, relações entre os colaboradores e desenvolvimento da análise das redes sociais (SCOTT, 1987). Relembrando, por exemplo, a Abordagem Clássica menciona sobre a relação existente entre a eficiência e o número de departamentos na estrutura organizacional, priorizando os aspectos formais. Na Teoria das Relações Humanas, a importância da formação de grupos sociais informais e por sua vez, na Teoria Comportamental ao enfocar os aspectos cognitivos dos trabalhadores, cuja ação de determinado indivíduo em relação ao grupo, incluíria as atividades (situações substantivas), os sentimentos (situações adjetivas) e a interação (situações verbais) esclareceria o comportamento organizacional (MINICUCCI, 1999).

Conforme estabelecidos pelas organizações, os organogramas configuram-se em uma projeção esquematizada da estrutura hierárquica mediante níveis de autoridade e respectivas linhas de relações formais, já determinando a priori os relacionamentos existentes. No entanto, Rank (2008) menciona que diante dessas interações formais, normalmente repetitivas e estáveis ao longo do tempo, uma segunda estrutura surge denominada como informal ou emergente, tendo seus padrões e expectativas do comportamento em torno do indivíduo que desenvolve sua própria estrutura a partir da casualidade, das características pessoais e da interação, formando redes de informação, amizade e confiança (KUIPERS, 1999).

Corroborando, Cross e Parker (2004) afirmam que a formação dos laços estão baseadas em seis dimensões: (1) Posição Hierárquica - tendenciosas devido à dependência por pessoas que ocupam determinadas posições hierárquicas, (2) Posição Organizacional - quando ficam mais no mesmo departamento, (3) Proximidade Física - relacionadas às distâncias físicas, (4) Estrutura de Interações - escolhas entre as fontes de informações que ajudam com as tarefas e atividades, (5) Tempo investido na manutenção de relacionamentos e (6) Tempo de Conhecimento. Assim, muitas vezes a criação das redes está relacionada às funções, rigidez na estrutura e ao grau de formalização (HARTMAN e JOHNSON,1990).

Dessa forma, o presente estudo tem como problema a seguinte indagação: "Quais são os condicionantes da formação das redes sociais em organizações pública e privada"?

Assim, este artigo tem como objetivo geral verificar os condicionantes que influenciam a formação das redes sociais de informação, amizade e confiança em organizações pública e privada. Os objetivos específicos são (i) mapear e caracterizar as redes sociais informais; (ii) identificar os atores centrais das redes; e (iii) verificar a influência da função na formação das redes, e (iv) constatar os motivos para a formação dos laços sociais. Buscando o alcance dos objetivos realizou-se uma pesquisa exploratória, de natureza quanti-qualitativa, desenvolvida por meio de um estudo de casos múltiplos.

A justificativa para a escolha de organizações pública e privada está na finalidade de constatar as implicações, atitudes e condutas dos indivíduos inseridos em duas situações contrastantes, já que 
elas se diferem quanto aos termos de financiamento, direito de propriedade e modo de controle, que provocam efeitos diversos no comportamento de seus funcionários (BOYNE, 2002; BAARSPULL, 2009). A escolha do estudo foi direcionada às escolas, pois embora a administração de empresas apresente tarefas semelhantes em essência à administração da educação, estas são muito distintas. A administração escolar difere quanto à sua natureza e características, tais como a avaliação do desempenho cujo processo de ensino-aprendizagem requer interação entre diversas pessoas em diferentes dimensões humanas e político-sociais (MARTINS, 1999; DOURADO, 2007). Destaca-se que atualmente, o Brasil encontra-se em processos de mudanças quanto a reforma escolar. Assim, este estudo apresenta contribuição prática, pois, a partir do reconhecimento das redes haverá a possibilidade de desenvolvimento de políticas e práticas de gestão, visando o estímulo ao empenho individual e coletivo para a realização de novos projetos e o alcance eficaz de suas metas, podendo ajudar os gestores e diretores a aproveitar o real poder de suas escolas, consertar a estrutura formal e deixar as relações informais prosperarem.

Neste contexto, o artigo encontra-se organizado em seis seções. A primeira trata da introdução do trabalho; a segunda fundamenta aspectos teóricos que envolvem as redes sociais, mencionando as redes de informação, amizade e confiança. A seção seguinte traz a metodologia que foi utilizada para a pesquisa, logo em seguida apresenta-se a análise dos resultados, dentro da sequência proposta pelos objetivos específicos, e as considerações acerca dos resultados do trabalho, as limitações e sugestões e, por fim, as referências bibliográficas utilizadas.

\section{REDES SOCIAIS}

Borgatti et al. (2009) mencionam que tanto a sociedade como a organização podem ser vistas imersas em uma imensa teia de relações e interações, assemelhando-se graficamente como um circuito de comunicação. Essas redes, que podem ser formais e informais, são caracterizadas pela formação de nós e linhas, cujo primeiro representa o indivíduo; e as linhas são os laços constróem e reconstróem a estrutura social (TOMAÉL e MARTELETO, 2006). Especificamente sobre as redes sociais informais, as relações estão baseadas por motivos sociais, organizacionais ou ambos, mas que não depende exclusivamente da combinação das tarefas e estrutura hierárquica.

A análise das Redes Sociais pode ser feita sob duas perspectivas. A primeira, baseada na Teoria dos Grafos, verifica a rede em si e suas características estruturais (tamanho, densidade, distância geodésica, e o diâmetro) e a segunda perspectiva, centrada em egos, estudam os atores, suas ligações e o papel deles nas redes (LAGO JUNIOR, 2005). Para o presente estudo será utilizada a primeira abordagem, conforme Quadro 1. 
Quadro 1: Perspectivas abordando as características estruturais da rede.

\begin{tabular}{|c|c|}
\hline $\begin{array}{l}\text { Características } \\
\text { estudadas da rede }\end{array}$ & Descrições \\
\hline Ator & É cada indivíduo setor ou departamento que está interligado à rede. \\
\hline Ligações & São representações gráficas de linhas que conectam os pontos (atores). \\
\hline Subgrupos & $\begin{array}{l}\text { São os subconjuntos de atores de uma determinada rede, os quais resultam de } \\
\text { aspectos que envolvem a localização, funções, hierarquia, idade, nível cultural, idade } \\
\text { ou sexo. }\end{array}$ \\
\hline Relação & É um tipo específico de ligações de um determinado grupo \\
\hline Tamanho & É a quantidade de ligações existentes entre os atores de uma rede. \\
\hline Densidade & $\begin{array}{l}\text { É o quociente entre o número de ligações existentes pelo número de ligações possíveis } \\
\text { em uma determinada rede. A densidade retrata a potencialidade da rede em termos de } \\
\text { fluxo de informações, ou seja, quanto maior a densidade mais intensa é a troca de } \\
\text { informações na referida rede e vice-versa. }\end{array}$ \\
\hline Distância Geodésica & É o caminho mais curto entre dois atores de uma rede. \\
\hline Diâmetro & É a maior distância geodésica entre quaisquer pares de atores da rede. \\
\hline
\end{tabular}
Fonte: Lago Junior (2005, p. 54).

Régis, Dias e Bastos (2006) corroboram ao afirmar que a Análise das Redes Sociais abrange três dimensões: cognitiva, estrutural e relacional. Segundo Nahapiet e Ghoshal (1998), a dimensão cognitiva representa as interpretações dos significados abrangendo a linguagem, os vocabulários e as narrativas compartilhadas pelos membros da rede, cujo conhecimento tácito de cada indivíduo serve de base para a compreensão da coletividade social, permitindo uma ligação entre mediadores como também se tornando fontes de interação social (RÉGIS, 2005).

Sobre a dimensão estrutural, esta acontece quando se faz uma determinação do padrão de ligações entre seus membros, ou seja, a proximidade qualificada pela intensidade dos laços. Para Granovetter (1973) esses laços podem ser fortes, cuja formação se faz devido ao tempo, intensidade emocional; e podem ser fracos, onde não há nenhum investimento mais profundo em se manter algo a não ser profissional, como ser alguém conhecido.

A dimensão relacional engloba no papel dos laços diretos entre os atores com os conteúdos transacionados. Nas análises de Krackhardt e Hanson (1993), as redes sociais da dimensão estrutural se dividem em três grupos de relacionamento, sendo eles, a rede de comunicação, de confiança e de aconselhamento. No entanto, para o presente estudo foi utilizado o estudo de Kuipers (1999) que abrange três abordagens: informação, amizade e confiança, conforme ilustra a Figura 1. 


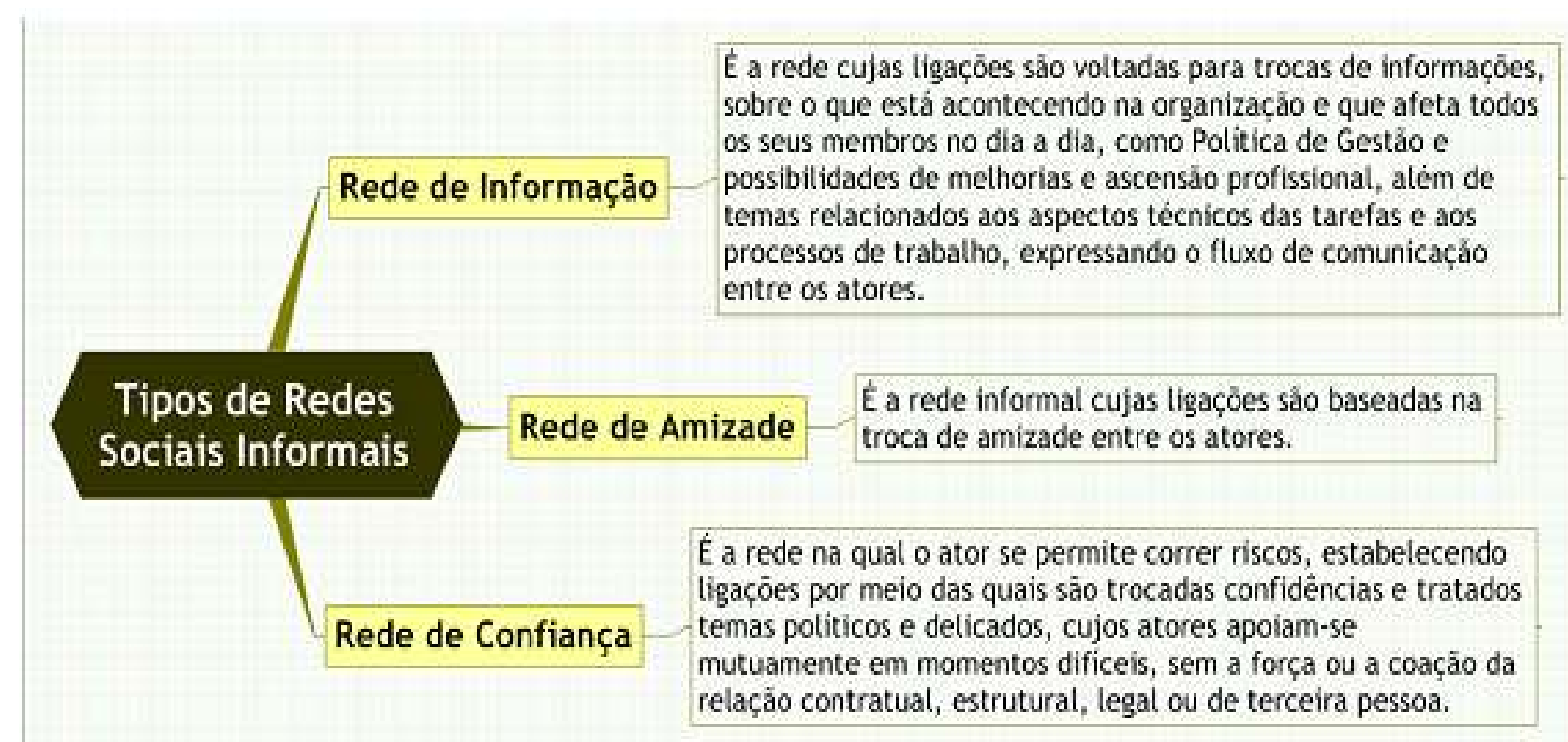

Figura 1: Tipos de Redes Sociais Informais.

Fonte: adaptado Kuipers, 1999 (apud MACAMBIRA, 2009, p. 51).

Sozen (2012) menciona que a análise de redes se centra na análise de dados provenientes de interações entre atores em vez de analisar o comportamento independente dos atores e que tem sido usada para revelar dinâmicas ocultas que moldam a vida social, organizacional e econômica. Para o autor, as vantagens estão associadas na procura de emprego, nas decisões de promoção dos funcionários, nos esforços de aquisição de recursos das organizações e na capacidade de inovação ou institucionalização de um setor.

Cross e Parker (2004) corroboram ao citar outros benefícios da análise das redes sociais (a) dá suporte de parcerias e alianças; (b) admite avaliação da execução da estratégia; (c) promove melhoria da aprendizagem e tomada de decisão estratégica das lideranças da Rede; (d) integra as redes por meio de processos centrais; (e) fomenta a inovação; (f) garante a integração pós-fusão ou mudança em larga escala; e (g) desenvolve comunidades de prática. Ao mesmo tempo, o mapeamento, as características, os tipos de ligação, o conteúdo transacionado dessas redes sociais informais permitirão a visualização de erros de comunicação, as estruturas frágeis e buracos estruturais da organização, como também a identificação de atores centrais, explorando uma suposta agilidade da organização informal sobre a formal (SOARES, 2008).

\section{MÉTODO DE PESQUISA}

O presente artigo é um estudo de casos múltiplos que conforme Gil (2002) tem como objetivo buscar um conhecimento amplo e detalhado de um ou mais objetos. Para Yin (2010), a escolha de casos múltiplos pode ser justificada por dois motivos, o primeiro por possuir efeitos semelhantes e o segundo por produzir resultados contrastantes. Dessa forma, o estudo justifica-se pela segunda opção, pois foram escolhidas duas escolas, uma pública e outra privada. 
Também possui como características ser exploratório e quali-quantitativo, pois tem no objetivo o desenvolvimento e aperfeiçoamento de novas ideias, utilizando de questionários, imagens e tabelas para explicar os resultados e suas relações. Neves (1996) menciona que os métodos qualitativos e quantitativos não se excluem, se complementam, pois através da combinação entre os dois gera a triangulação, tem a possibilidade de congregar a identificação e o controle dos vieses (quantitativo) com a compreensão da perspectiva dos agentes envolvidos no fenômeno por meio de uma visão global (qualitativo).

Este trabalho está dividido em quatro etapas, sendo a primeira referente ao perfil do entrevistado, isto é, o nome, função, gênero, escolaridade, primeira e atual função na organização, tempo de serviço e forma de contratação. Buscou-se entrevistar todos os funcionários das escolas, totalizando 66 colaboradores na escola pública e 73 na escola particular. É importante para o mapeamento das redes sociais, obter a totalidade dos respondentes, porque a falta de algum participante pode ocasionar danos na identificação de atores centrais, bem como a formação de viesses indesejáveis (MACAMBIRA, 2009). Destaca-se que utilizando o critério de exclusão, os funcionários das escolas que se encontravam em períodos de licença e/ou tempo noturno não participaram da pesquisa, tampouco poderiam ser mencionados.

A segunda etapa, caracterizada pela identificação e mapeamento das redes sociais informais, foi baseada em Kuipers (1999) e Silva (2003): "Relembrando os últimos seis meses, quais foram as pessoas de seu ambiente de trabalho que Ihe deram informações importantes, que lhe ajudaram na organização?"(Rede Social de Informação - RSI); "Relembrando os últimos seis meses, quais pessoas de seu ambiente de trabalho foram importantes fontes de amizade?" (Rede Social de Amizade - RSA); "Relembrando os últimos seis meses, quais foram as pessoas do seu ambiente de trabalho que você realmente confiou? Que você se sentiu confortável para correr riscos profissionais sem temer consequências negativas?" (Rede Social de Confiança - RSC). Para cada relação, os entrevistados foram solicitados a citar a quantidade de pessoas que julgassem como verdadeiro, pois os nomes seriam codificados posteriormente por nomes de flores para a escola pública e tipos de árvores de nacionalidade brasileira para a escola privada.

A terceira etapa refere-se à justificativa dos motivos da formação de laços por todos os respondentes. Baseado em Sozen (2012), as perguntas estavam relacionadas com a dependência em tarefas, motivos e consequências de um não relacionamento com cada citação mencionada. $E$ após descoberto os cinco atores centrais de cada rede, quarta etapa, foi feita uma entrevista com essas pessoas buscando identificar os motivos que eles acreditam ser a razão do número de citações recebidas.

Deste modo, participaram da pesquisa dezoito colaboradores, sendo nove de cada escola, por meio de entrevista semi-estruturada, guiada por um roteiro (protocolo) pré-estabelecido a fim de diagnosticar se os condicionantes da relação estavam associados às seis dimensões de Cross e Parker (2004): Posição Hierárquica, Posição Organizacional, Proximidade Física, Estrutura de Interações, Tempo investido na manutenção de relacionamentos e Tempo de Conhecimento.

Para a análise das Redes Sociais empregou-se o software Ucinet 6.0 em paralelo com o NetDraw. Já as entrevistas foram gravadas (com a autorização do respondente) e transcritas, 
resultando na qualificação das informações e identificação dos elementos para a análise. Yin (2010) menciona que a utilização de um software auxilia na codificação e categorização dos dados, permitindo definir um conjunto de categorias e posteriormente a contagem da incidência ou ocorrência das palavras. Para este estudo, empregou-se o NVivo sendo feita a contagem de quantas vezes determinada palavra foi citada nas categorias. Ao final, foi realizada a análise de conteúdo à visão de Bardin (2006). Assim, as entrevistas foram submetidas a sucessivas leituras de modo a identificar a presença de certos conteúdos, cujas características foram organizadas em categorias de respostas.

\section{ANÁLISE DOS RESULTADOS}

Sobre a caracterização da pesquisa realizada em uma escola pública e uma privada na cidade de Ponta Porã, MS, percebeu-se que houve a predominância de funcionários do gênero feminino na Escola Privada $(90,9 \%)$ e na Pública (58,91\%). Bem como, 42,40\% trabalham no período vespertino na Escola Pública e 43,83\% no período integral na Escola Privada. O maior tempo de serviço na escola pública foi entre mais de 5 até 10 anos (30,3\%) e na escola privada foi de mais de 1 até 5 anos (39,73\%). Além disso, a maioria possuía pós-graduação na Escola Pública $(48,38 \%)$ e na Escola Privada (35,62\%), demonstrando elevada escolaridade entre os funcionários das escolas pesquisadas. Quanto ao motivo de ingresso na rede pública, $87,85 \%$ disseram que foi por meio de Concurso Público e na rede privada $52,05 \%$ afirmaram que foi por indicação. Por fim, a maioria dos pesquisados não passou por mudança na sua vaga tanto na escola pública $(72,7 \%)$ quanto na privada $(76,75 \%)$.

\section{Redes Sociais de Informação - RSI}

Considerando que as relações informais são derivadas de causas organizacionais, características e interações pessoais ou pelo conjunto delas (KUIPERS, 1999; SOUZA e DIAS, 2008), podendo, portanto, ser exclusivamente relacionada com as qualidades pessoais sem o vínculo formal, como também pelos dois, o cálculo do número total de relações informais possíveis é realizado quando existe a multiplicação do número total de nodos pelo número total de nodos menos um. Assim, para a Escola Pública, o número total de possíveis relações é de 4.290 [(66x(65-1)] e para a Escola Privada 5.256 [73x(73-1)]. Nos Quadros 2 e 3 podem ser visualizados os mapas das Redes de informação das escolas e suas características. 
Quadro 2: Redes Sociais de Informação Escola Pública

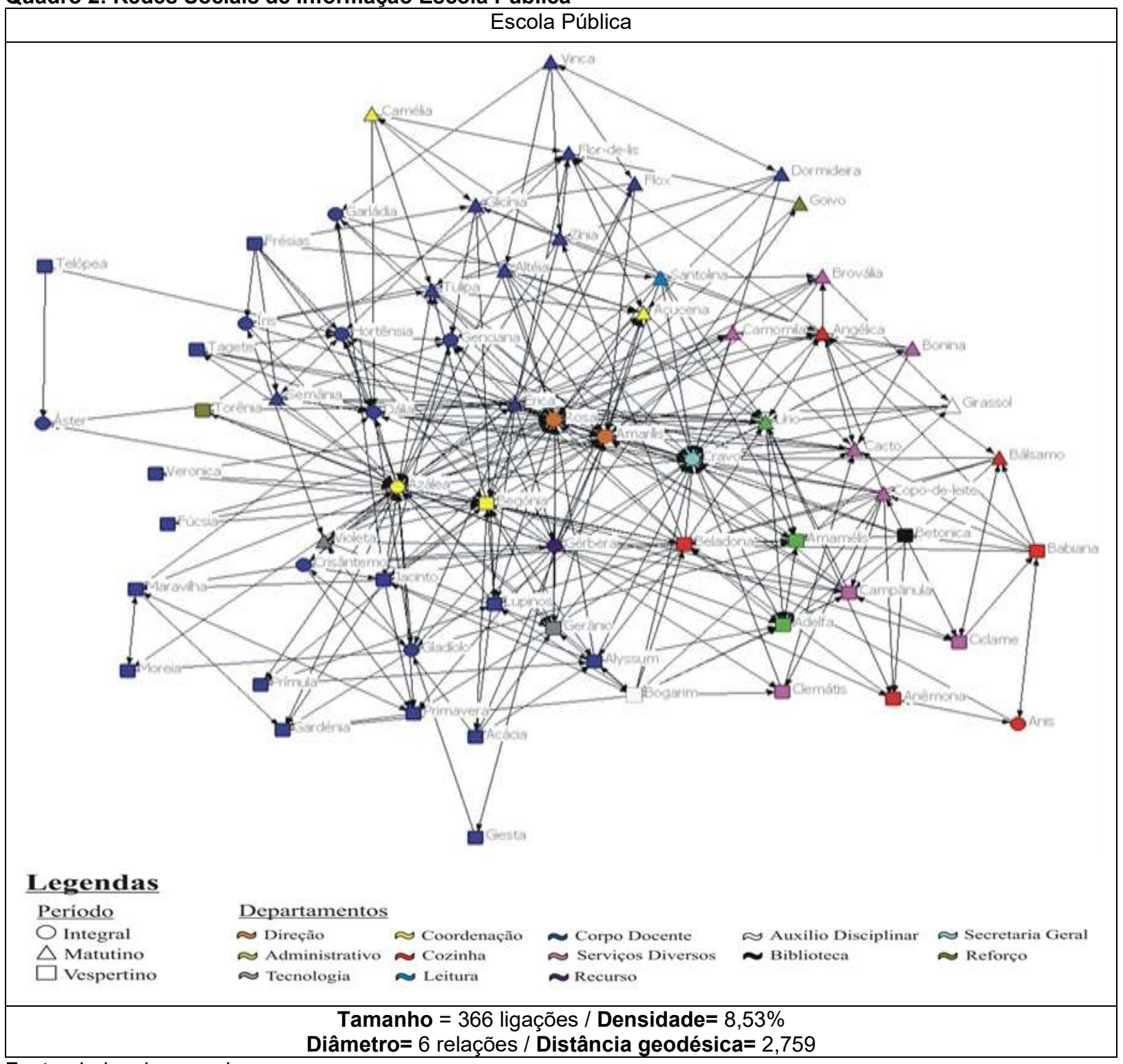

Fonte: dados da pesquisa.

Na maioria das vezes, as organizações públicas são caracterizadas pela estrutura burocrática rígida, demonstrando o formalismo das relações e reduzindo os canais de comunicação com as informações disponíveis em função da alta centralização. Porém, no caso da Escola Pública pesquisada, apesar do número de relações formais (doravante às tarefas organizacionais e estrutura hierárquica) ser maior, ressalta-se a quantidade de laços informais existentes (154), conforme visualizado na Figura 2. 


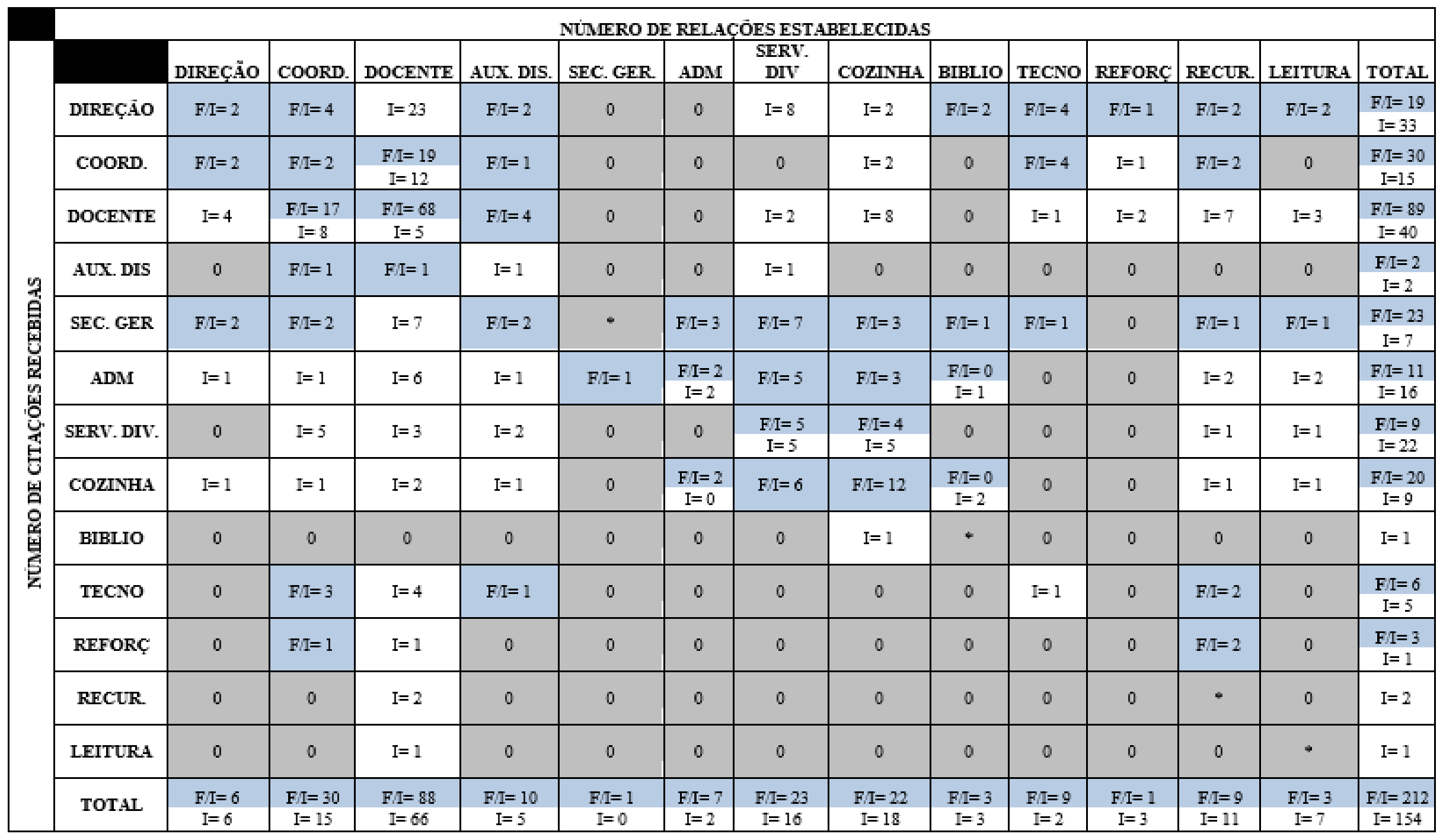

Figura 2: RSII por departamento - Escola Pública. Fonte: Dados da pesquisa
(*): Há somente um indivíduo no departamento, excluindo a possibilidade de autocitação. (F/l): Relação Formal/Informal

(I): Relação exclusivamente informal 
De acordo com a Figura 2, a Direção da Escola Pública é citada por quase todos os departamentos, evidenciando flexibilidade aos canais de informação. Embora o Corpo Docente apresente quantia superior no total de integrantes, na ordem de 33 indivíduos, este setor recebeu 40 citações informais, cujas relações, além daqueles com a área pedagógica, situam-se com os setores: Serviços Diversos, Cozinha, Tecnologia, Reforço, Recurso e Leitura. O motivo pode estar relacionado ao fato desses departamentos serem formados por professores que passaram por mudança na função, mas que em momentos de intervalo encontram-se no mesmo ambiente que os demais docentes.

Outro fator a ser ressaltado é a pouca quantidade de relações recebidas por alguns departamentos, como Tecnologia, Reforço, Recurso, Leitura e Biblioteca, concomitante aos outros setores que estabeleceram vínculos de informação somente com as mesmas áreas (Secretaria Geral e Administrativo na área administrativa, e o Reforço Escolar com a área pedagógica) não demonstrando a reciprocidade dos laços de informação.

Em contraponto, a Escola Privada (Quadro 3 e Figura 3) apresentou maior número de relações formais/informais, mas menos relacionamentos exclusivamente informais que a Escola Pública.

\section{Quadro 3: Redes Sociais de Informação Escola Privada}

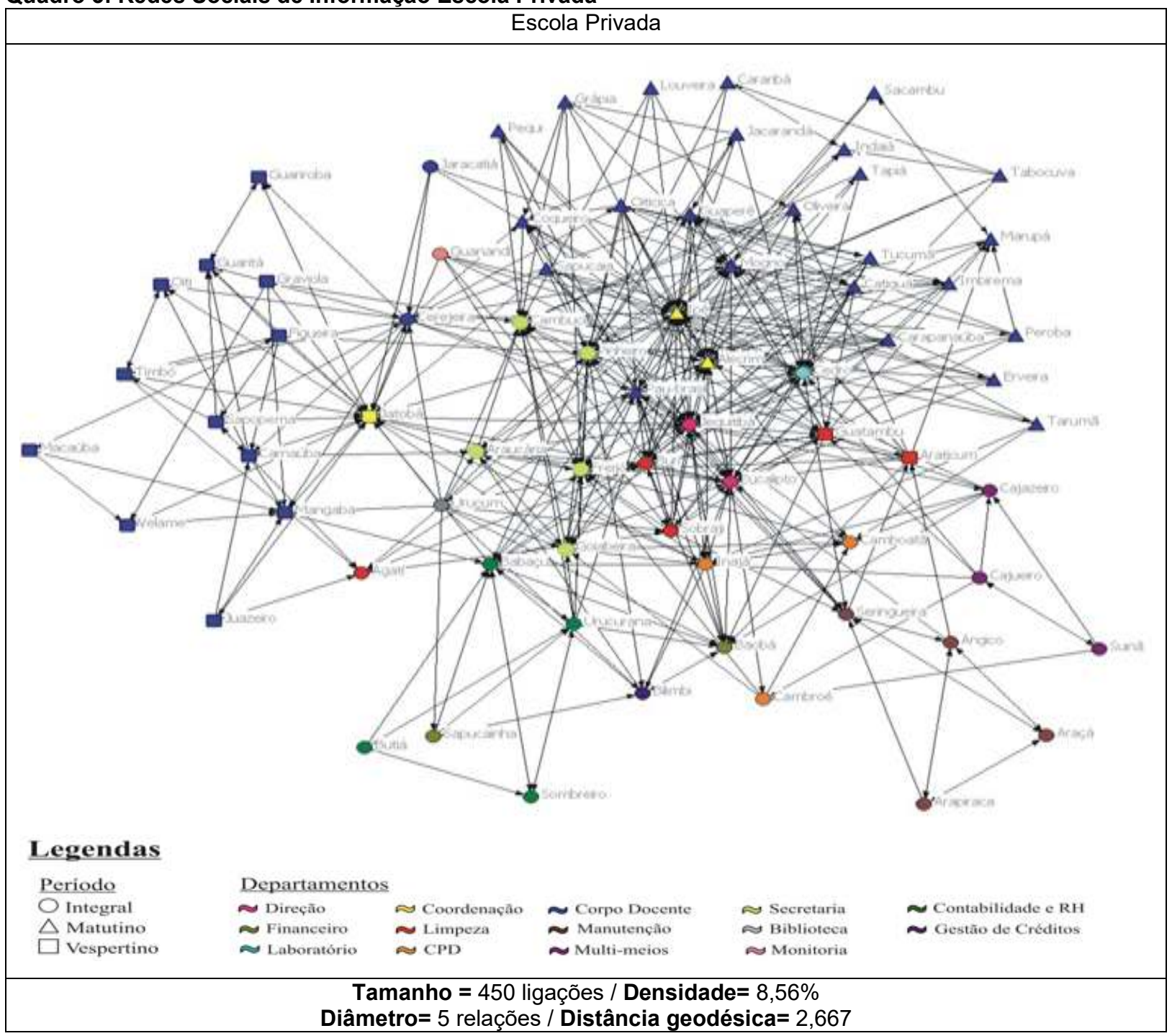

Fonte: dados da pesquisa.

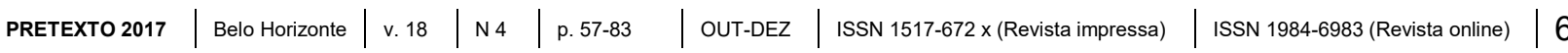




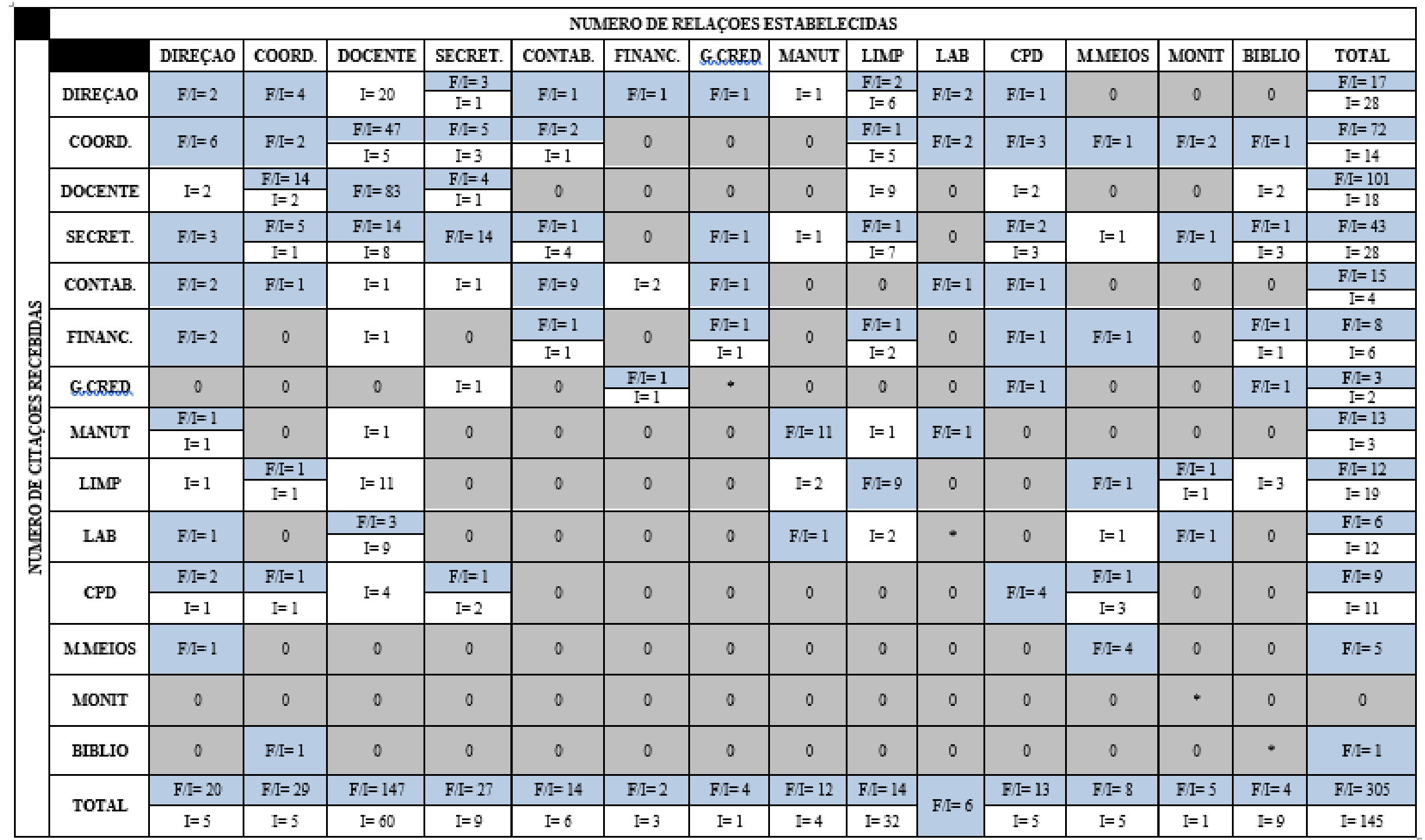

Figura 3: RSII por departamento - Escola Privada.

Fonte: Dados da pesquisa. $\left.{ }^{*}\right)$ Há somente um indivíduo no departamento, excluindo a possibilidade de autocitação. (F/I): Relação Formal/Informal 
Conforme visualizado na Figura 3, a Direção comunicou-se com quase todos os departamentos, principalmente com aqueles que são chefes do setor. A diretora pedagógica não segue apenas os níveis hierárquicos formais desenhados pela estrutura organizacional, pelo fato de cultivar vínculos com parte do Corpo Docente, aproveitando o intervalo para o contato com os professores, possibilitando o esclarecimento de dúvidas, sugestões de projetos, orientações e conselhos além dos recebidos nos encontros periódicos.

Por sua vez, as coordenadoras conquistaram maior número de relações formais do que informais, cujos $65 \%$ eram originários dos laços com seus subordinados diretos, isto é, com o Corpo Docente. Os laços formados com aqueles de níveis hierárquicos mais altos estão geralmente relacionados à tomada de decisão, aquisição de recursos entre outros, que acabam exigindo competência imediata (CROSS e PARKER, 2004).

O papel das secretárias na Rede Social Informal de Informação da Escola Privada é importante, pelo motivo delas estabeleceram relações formais e informais com quase todos os departamentos, com exceção do Laboratório e Financeiro. No caso desta escola, cada secretária é subordinada a uma coordenadora e à secretária geral, aumentando as possibilidades de relacionamentos formais com os professores. Sozen (2012) menciona que a secretária atinge status na Rede, pois é geralmente responsável pela elaboração de documentos oficiais, fornecendo a comunicação escrita entre os setores, além do fato de gerir a circulação burocrática de acordo com as normas da organização.

Destaca-se o fato de a monitora não ter recebido citação, fato que pode ser explicado pelo pouco tempo de serviço (um mês), não permitindo ser propulsora de informações; bem como o fato de o chefe do Laboratório formar somente relações formais, apesar do mesmo atribuir à função de inspetor no horário de entrada, intervalo e saída dos alunos.

Assim, corroborando com Cross e Parker (2004) as duas escolas evidenciaram que as relações são formadas por critérios que envolvem a posição hierárquica e organizacional, já que houve mais relações formais do que exclusivamente informais; proximidade física e estrutura de interações, uma vez analisada a relação entre os departamentos, os laços se formaram mais nos mesmos setores, e tempo investido na manutenção de relacionamentos, pois aqueles que estão há menos tempo na organização foram menos citados.

\subsection{Rede Social de Amizade - RSA}

Considerando a possibilidade de haver 4.290 relações de amizade na Escola Pública, e 5.256 na Escola Privada, o quadro 4 ilustra os mapeamentos das RSA e as suas características.

Ao considerar que a densidade retrata a potencialidade da rede em termos de fluxo e que quanto maior, mais intensa é a rede, destaca a densidade da Escola Pública ser superior à da Escola Privada. Associa-se ao motivo da ausência de pressões competitivas na Escola Pública, tanto em nível organizacional como individual, porque os gestores públicos freqüentemente desfrutam de uma posição dominante no mercado (BOYNE, 2002) e também seus colaboradores apresentam estabilidade na função (BERGUE, 2005). 
Quadro 4: Redes Sociais de Amizade.

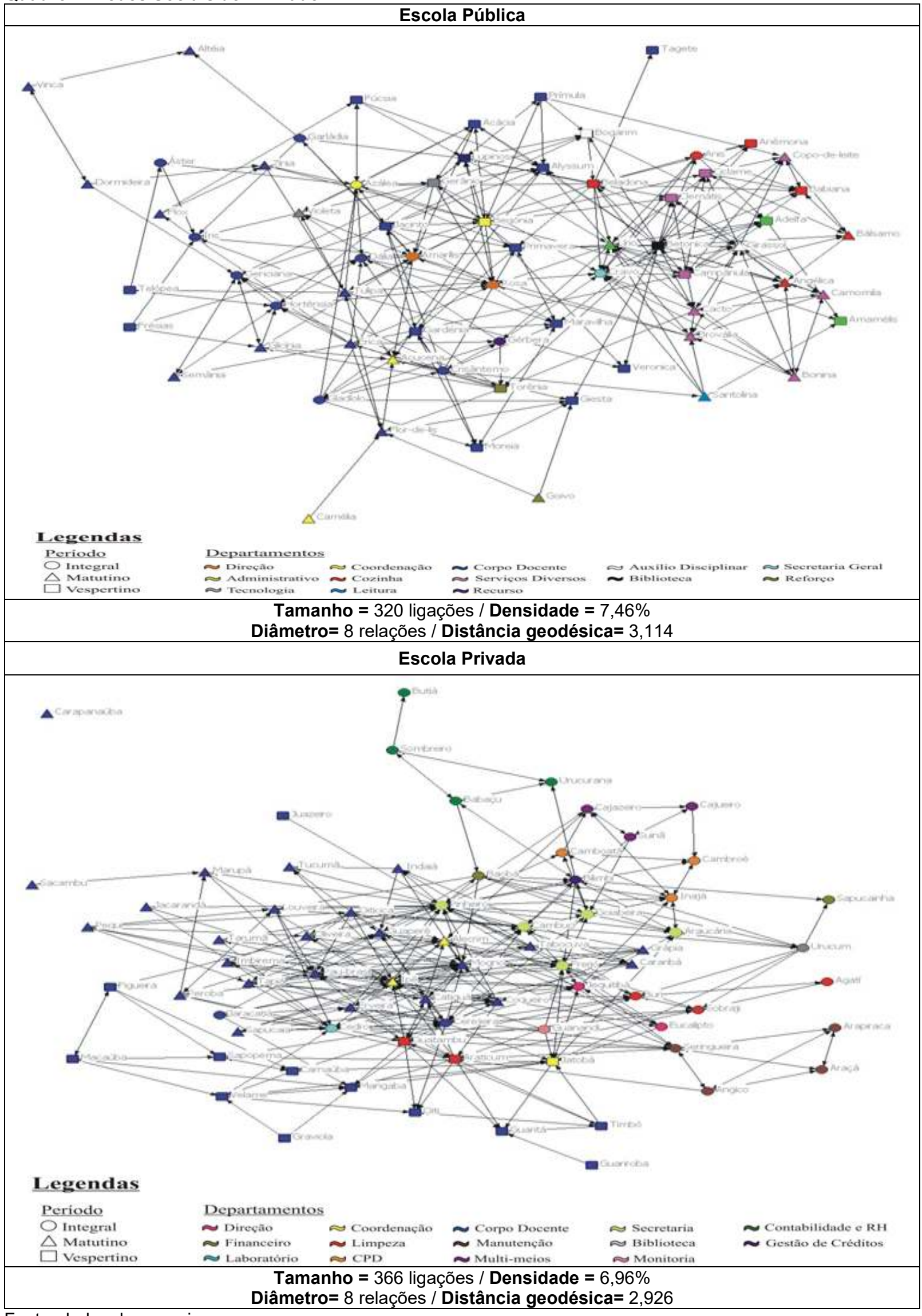

Fonte: dados da pesquisa. 


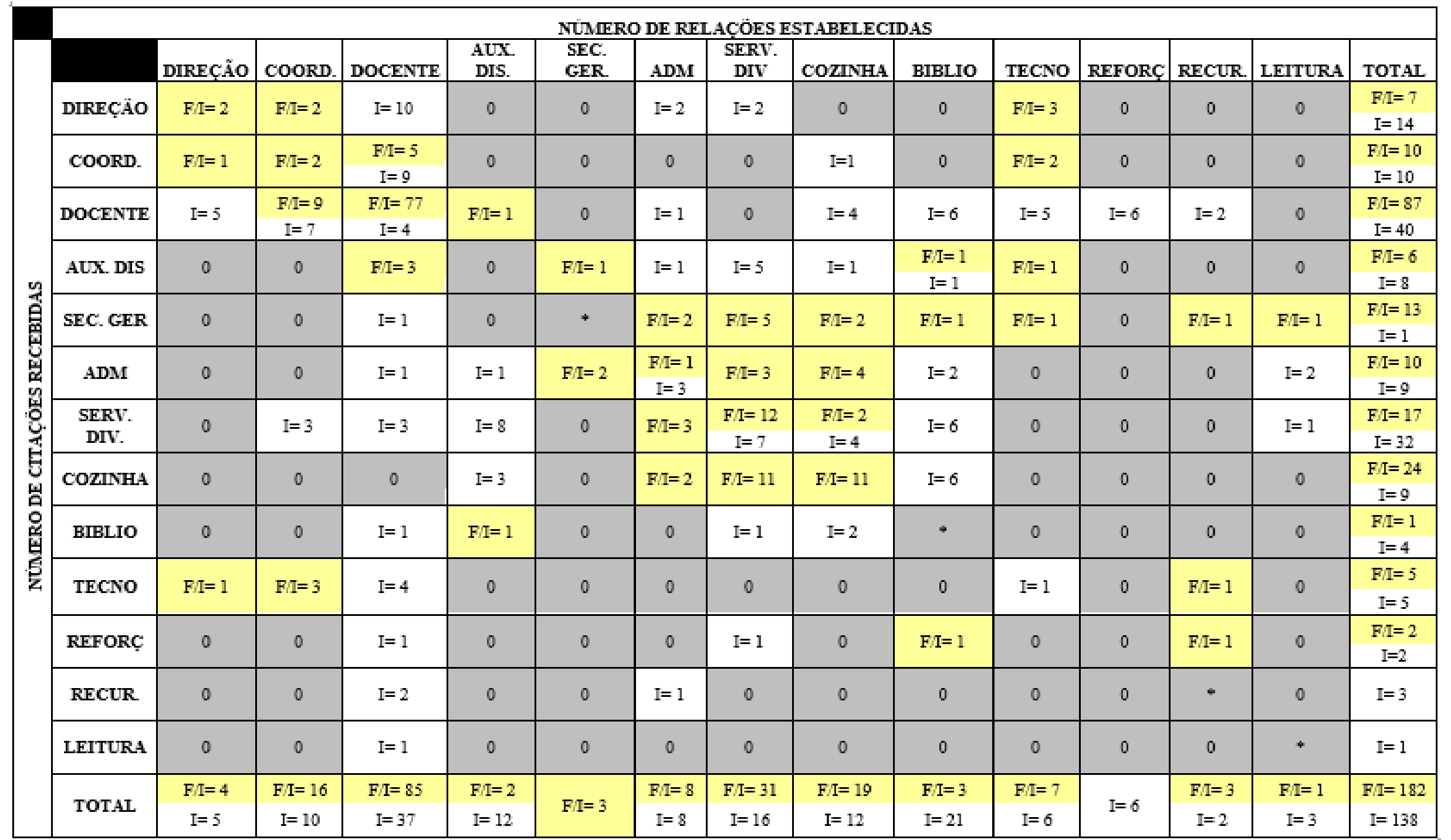

Figura 4: RSIA por departamento - Escola Pública. Fonte: Dados da pesquisa
(*): Há somente um indivíduo no departamento, excluindo a possibilidade de autocitação. (F/I): Relação Formal/Informal (I): Relação exclusivamente informal

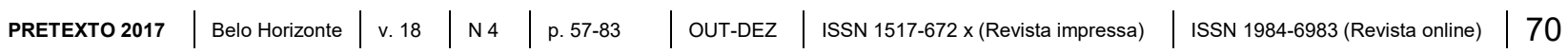


Ao analisar as relações entre os departamentos da Escola Pública (Figura 4), percebeu-se que as relações de estima permaneceram na mesma área de atuação, ou seja, a Direção, Coordenação e o Corpo Docente mantiveram o maior número de vínculos entre si; além disso, a Área Administrativa da escola (setores da Cozinha, Serviços Diversos e Administrativo) evidenciaram considerável reciprocidade entre suas relações.

Ressalta-se que alguns departamentos não expressaram afeição pela Direção, demonstrando que os laços de amizade estão muito mais caracterizados pelas semelhanças sociais, reais e percebidas do que pelo poder que o cargo ostenta. Por outro lado, os relacionamentos com o secretário geral, responsável pelos cozinheiros, auxiliares de serviços diversos e administrativo, mostrou que a maioria dos laços de amizade ocorreram a partir da formalidade das funções. No entanto, a proximidade, o habitual contato e os padrões de interação forçadas pela dependência das tarefas tornou-se base para o surgimento da amizade (MCGRATH e KRACKHARDT, 2003).

O departamento do Corpo Docente possui $50 \%$ do total dos membros da Escola Pública e apresentou maior número de relações de amizade entre si e com os demais setores. Bem como, os responsáveis atuais pela Direção, Coordenação, Tecnologia, Recurso, Reforço e Leitura permaneceram apresentando vínculos afetivos, mesmo depois de sair do cargo de professor.

A Figura 5 apresenta a Rede de Amizade da Escola Privada por departamentos, cujos laços estavam também baseados nos vínculos formais existentes: as relações formadas entre a Área Pedagógica (Direção, Coordenação e Corpo Docente), e quando considerado cada setor, o maior número de relações estabelecidas encontrava-se entre os mesmos departamentos (Manutenção $x$ Manutenção, Limpeza x Limpeza, Multi-meios x Multi-meios, Corpo Docente x Corpo Docente, e Contabilidade $x$ Contabilidade).

Ressalta-se também as secretárias conseguiram manter os relacionamentos amigáveis com quase todos os outros departamentos e que os setores da Contabilidade, Coordenação, Laboratório e Monitoria estabeleceram amizade somente com aquelas pessoas que possuíam relações formais a priori. Dessa maneira, nas duas escolas, a posição organizacional, proximidade física, estrutura de interações e o tempo investido na manutenção de relacionamentos definiram a formação da rede de amizade e, não a posição hierárquica entre os colaboradores. 


\begin{tabular}{|c|c|c|c|c|c|c|c|c|c|c|c|c|c|c|c|c|}
\hline & \multicolumn{16}{|c|}{ NUMERO DE RELACCOES ESTABELECIDAS } \\
\hline \multirow{16}{*}{ 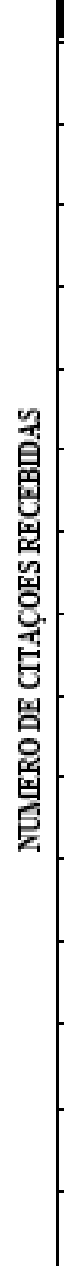 } & & DIREÇAO & COORD. & DOCENTE & SECRET. & CONTAB. & FINANC. & GCRED & MANUT & LMP & LAB & CPD & M.MEIOS & MONIT & BIBLIO & TOTAL \\
\hline & DIREÇAO & $F /=2$ & $F /=2$ & $I=3$ & $\mathrm{~F} / \mathrm{I}=\mathbf{2}$ & 0 & 0 & 0 & 0 & 0 & 0 & 0 & 0 & 0 & 0 & $\begin{array}{c}\mathrm{F} / \mathrm{I}=6 \\
\mathrm{I}=3\end{array}$ \\
\hline & COORD. & $F / I=6$ & $F /=2$ & $\begin{array}{c}\mathrm{F} / \mathrm{I}=22 \\
\mathrm{I}=3\end{array}$ & $\begin{array}{c}\mathrm{F} / \mathrm{I}=3 \\
\mathrm{I}=1\end{array}$ & 0 & 0 & 0 & 0 & $\begin{array}{c}F / I=1 \\
I=1\end{array}$ & $\mathrm{~F} / \mathrm{I}=1$ & 0 & $F / I=1$ & $F / I=2$ & $F /=1$ & $\begin{aligned} \mathrm{F} / \mathrm{I} & =39 \\
\mathrm{I} & =5\end{aligned}$ \\
\hline & DOCENTE & $\mathrm{I}=2$ & $\mathrm{~F} / \mathrm{I}=10$ & $\mathrm{~F} / \mathrm{I}=106$ & $F / 1=11$ & 0 & $I=3$ & 0 & 0 & $\mathrm{I}=12$ & 0 & 0 & 0 & 0 & 0 & $\begin{array}{c}\mathrm{F} / \mathrm{I}=127 \\
\mathrm{I}=17\end{array}$ \\
\hline & SECRET. & $\mathrm{F} / \mathrm{I}=2$ & $F /=4$ & $\begin{array}{c}\mathrm{F} / \mathrm{I}=13 \\
\mathrm{I}=8\end{array}$ & $F / I=10$ & 0 & $\begin{array}{c}\mathrm{F} / \mathrm{I}=1 \\
\mathrm{I}=2\end{array}$ & $\begin{array}{c}\mathrm{F} / \mathrm{I}=2 \\
\mathrm{I}=3\end{array}$ & $I=1$ & $I=2$ & 0 & $\begin{array}{c}F /=1 \\
I=3\end{array}$ & $I=3$ & $F / I=1$ & $F /=1$ & $\begin{array}{c}\mathrm{F} / \mathrm{I}=35 \\
\mathrm{I}=22\end{array}$ \\
\hline & CONTAB & 0 & 0 & 0 & 0 & $F / I=7$ & 0 & $\begin{array}{c}\mathrm{F} / \mathrm{I}=1 \\
\mathrm{I}=1\end{array}$ & 0 & 0 & 0 & 0 & 0 & 0 & 0 & $\begin{array}{c}\mathrm{F} / \mathrm{I}=8 \\
\mathrm{I}=1\end{array}$ \\
\hline & FINANC. & 0 & 0 & 0 & $\begin{array}{c}F /=1 \\
I=1\end{array}$ & $F / I=1$ & 0 & $\begin{array}{c}F / I=1 \\
I=1\end{array}$ & 0 & 0 & 0 & $\mathrm{~F} / \mathrm{I}=1$ & 0 & 0 & $\begin{array}{c}F /=1 \\
I=1\end{array}$ & $\begin{array}{c}F / I=5 \\
I=3\end{array}$ \\
\hline & GCRED & 0 & 0 & 0 & $I=3$ & $\mathrm{~F} / \mathrm{I}=1$ & $F / I=1$ & - & 0 & 0 & 0 & 0 & 0 & 0 & $\mathrm{~F} / \mathrm{I}=1$ & $\begin{array}{c}\mathrm{F} / \mathrm{I}=3 \\
\mathrm{I}=3\end{array}$ \\
\hline & MANUT & 0 & 0 & $\mathrm{I}=2$ & $F / I=1$ & 0 & 0 & 0 & $\mathrm{~F} / \mathrm{I}=12$ & $\begin{array}{c}\mathrm{F} / \mathrm{I}=1 \\
\mathrm{I}=1\end{array}$ & $F / I=1$ & 0 & 0 & 0 & 0 & $\begin{array}{c}\mathrm{F} / \mathrm{I}=15 \\
\mathrm{I}=3\end{array}$ \\
\hline & LDPP & 0 & 0 & $I=11$ & $\mathrm{I}=2$ & 0 & 0 & 0 & $\mathrm{I}=2$ & $F / I=14$ & 0 & 0 & 0 & 0 & $\mathrm{I}=2$ & $\begin{array}{c}\mathrm{F} / \mathrm{I}=14 \\
\mathrm{I}=17\end{array}$ \\
\hline & $L A B$ & 0 & 0 & $\begin{array}{c}\mathrm{F} / \mathrm{I}=2 \\
\mathrm{I}=10\end{array}$ & 0 & 0 & 0 & 0 & $F /=1$ & 0 & $*$ & 0 & 0 & $F / I=1$ & 0 & $\begin{array}{l}F / I=4 \\
I=10\end{array}$ \\
\hline & CPD & $F / 1=1$ & 0 & 0 & $\begin{array}{c}F /=1 \\
I=6\end{array}$ & 0 & 0 & 0 & 0 & 0 & 0 & $\mathrm{~F} /=5$ & $\begin{array}{c}\mathrm{F} / \mathrm{I}=1 \\
\mathrm{I}=1\end{array}$ & 0 & 0 & $\begin{array}{c}\mathrm{F} / \mathrm{I}=8 \\
\mathrm{I}=7\end{array}$ \\
\hline & MLIEIOS & 0 & 0 & 0 & $\mathrm{I}=1$ & 0 & 0 & 0 & 0 & 0 & 0 & $\begin{array}{c}\mathrm{F} / \mathrm{I}=1 \\
\mathrm{I}=1\end{array}$ & $F / I=6$ & 0 & 0 & $\begin{array}{c}\mathrm{F} / \mathrm{I}=7 \\
\mathrm{I}=2\end{array}$ \\
\hline & MONIT & 0 & 0 & 0 & 0 & 0 & 0 & 0 & 0 & 0 & 0 & 0 & 0 & • & 0 & 0 \\
\hline & BIBLIO & 0 & 0 & $\mathrm{I}=1$ & 0 & 0 & 0 & $F / I=1$ & 0 & 0 & 0 & 0 & 0 & 0 & $*$ & $\begin{array}{c}\mathrm{F} / \mathrm{I}=1 \\
\mathrm{I}=1\end{array}$ \\
\hline & TOTAL & $\begin{array}{c}\mathrm{F} / \mathrm{I}=11 \\
\mathrm{I}=2\end{array}$ & $F /=18$ & $\begin{array}{c}\mathrm{F} / \mathrm{I}=143 \\
\mathrm{I}=38\end{array}$ & $\begin{array}{c}\mathrm{F} / \mathrm{I}=29 \\
\mathrm{I}=14\end{array}$ & $F / I=9$ & $\begin{array}{c}F / I=2 \\
I=5\end{array}$ & $\begin{array}{c}F / I=5 \\
I=5\end{array}$ & $\begin{array}{c}\mathrm{F} / \mathrm{I}=13 \\
\mathrm{I}=3\end{array}$ & $\begin{array}{c}F / I=16 \\
I=16\end{array}$ & $F /=2$ & $\begin{array}{c}F /=8 \\
I=4\end{array}$ & $\begin{array}{c}F / I=8 \\
I=4\end{array}$ & $F / I=4$ & $\begin{array}{c}F I=4 \\
I=3\end{array}$ & $\begin{array}{c}\mathrm{F} I \mathrm{I}=272 \\
\mathrm{I}=94\end{array}$ \\
\hline
\end{tabular}

Figura 5: RSIA por departamento - Escola Privada Fonte: Dados da pesquisa.
(*): Há somente um indivíduo no departamento, excluindo a possibilidade de autocitação (F/I): Relação Formal/Informal
(I): Relação exclusivamente informal

\begin{tabular}{l|l|l|l|l|l|l|l} 
PRETEXTO 2017 & Belo Horizonte & v. 18 & N 4 & p. 57-83 & OUT-DEZ & ISSN 1517-672 x (Revista impressa) & ISSN 1984-6983 (Revista online) \\
72
\end{tabular} 


\subsection{Rede Social Informal de Confiança - RSC}

Kuipers (1999) afirma que a Rede Social de Confiança (RSC) terá tamanho inferior às outras redes em razão do tempo que ela exige para sua formação. Deste modo, conforme Quadro 5, o tamanho da RSC da Escola Pública foi de 157 e da Escola Privada 217 relações.

Quadro 5: Redes Sociais de Confiança.

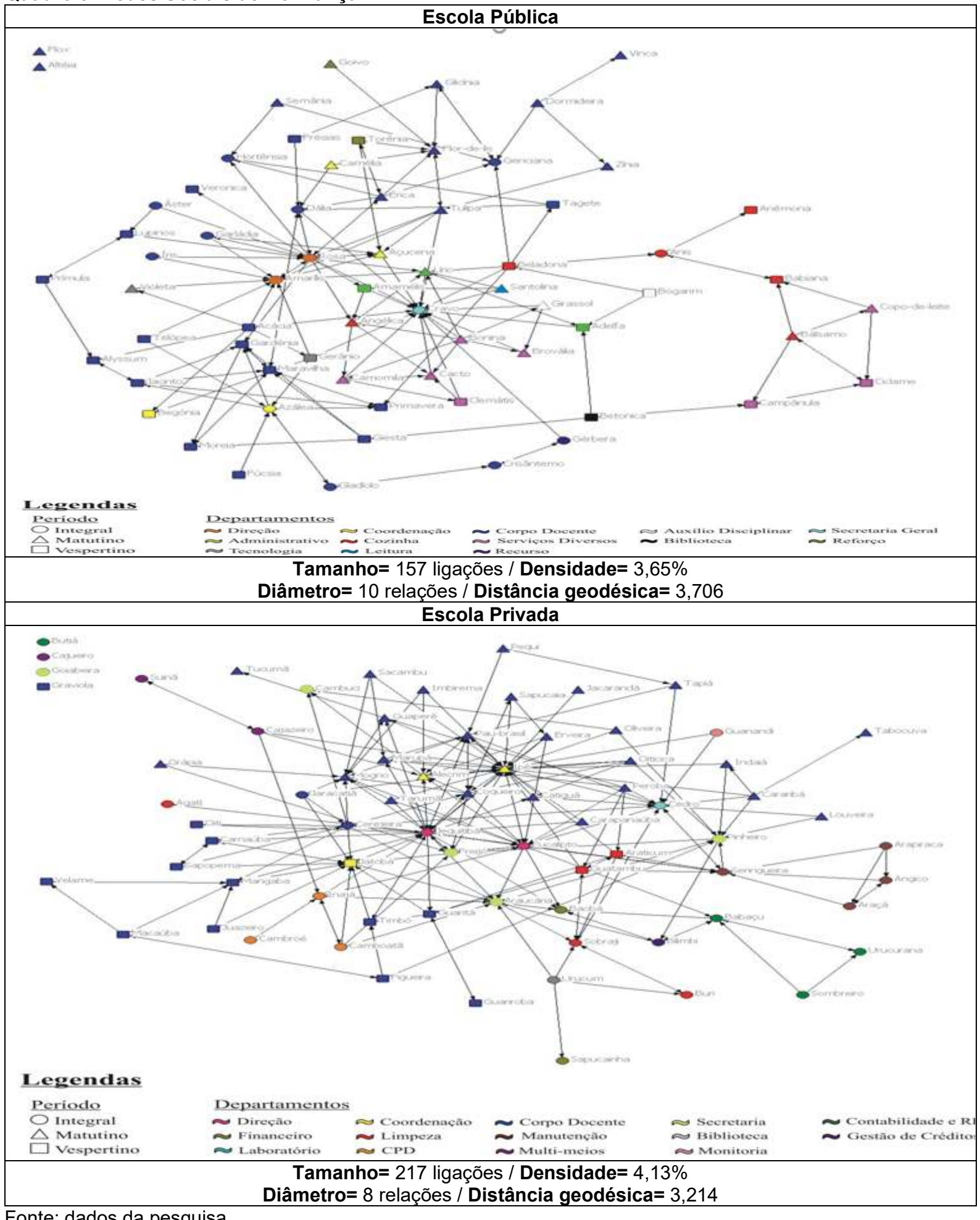

Fonte: dados da pesquisa. 
Verifica-se que em ambas as Redes de Confiança apresentaram atores isolados, isto é, não citaram e não foram citados. Pode-se afirmar que diante o pouco tempo de serviço nas Escolas eles não criaram condições para a formação do laço. No entanto, Gordon (2006) afirma que a confiança pode ter significado diferente para as pessoas.

De modo geral, conforme a Figura 6, todos os setores apresentaram situações onde não existe confiança entre eles. Destaca-se que não houve reciprocidade entre os atores que estabeleceram e receberam laços. Por exemplo, Secretaria Geral alcançou 18 citações, no entanto, não formou nenhuma relação, e os departamentos da Biblioteca e Leitura não obtiveram vínculos de confiança. Evidencia-se também que o Corpo Docente e o Administrativo foram indicados por outros departamentos, todavia, mais em sua área de atuação (Pedagógica e Administrativa, respectivamente).

Quando analisada a RSC da Escola Privada por departamentos, ilustrada na Figura 7, sete departamentos (Coordenação, Contabilidade, Financeiro, Gestão de Créditos, Laboratório, Multi-meios e Monitoria) estabeleceram relações de confiança com aqueles que possuem um laço formal, seja pela subordinação ou pela mesma função. Destaca-se que a Coordenação instituiu vínculos de confiança com a Área Pedagógica, e que os Departamentos da Contabilidade, Financeiro e Gestão de Créditos mais com a Área Administrativa.

Tratando-se da quantidade de citações recebidas, os setores da Contabilidade, Financeiro, CPD e Multi-meios obtiveram indicações de confiança somente com aqueles que já têm um convívio mais formal. $\mathrm{Na}$ análise da relação intradepartamental verificou-se que mesmo o Corpo Docente apresentando maior número de colaboradores, os mesmos se relacionam exclusivamente com os professores de mesmo período já institucionalizado pela escola.

Enfatiza-se que a Direção constituiu o maior número de relações de confiança entre os departamentos, totalizando oito setores, corroborando com Brei e Rossi (2005) quando mencionam que a confiança pode estar relacionada na crença da ação responsável e esperada. Dessa forma, nas duas escolas, a dimensão "posição hierárquica" de Cross e Parker (2004) influenciou diretamente a formação dos laços de confiança. 


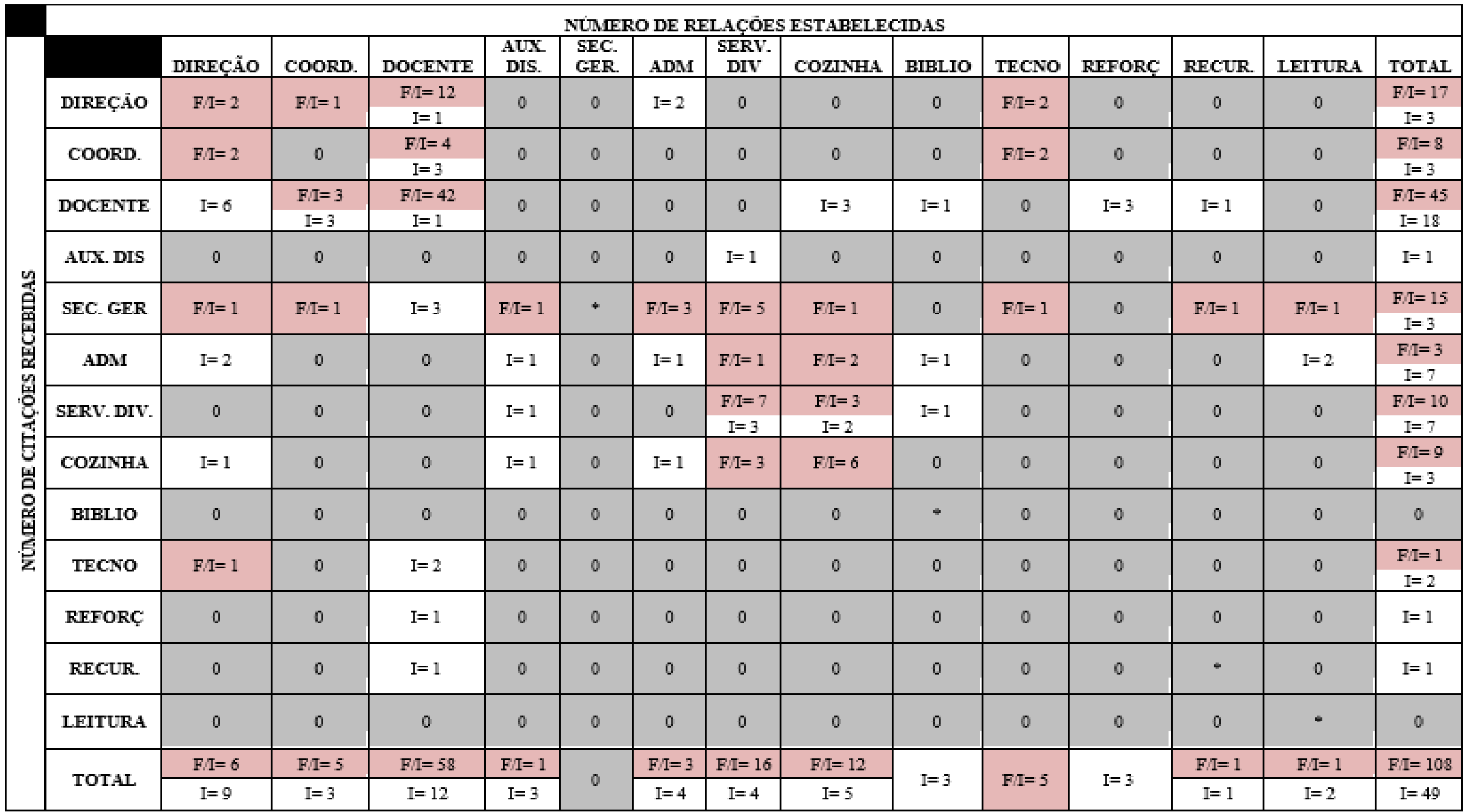

Figura 6: RSIC por departamento - Escola Pública. Fonte: Dados da pesquisa
(*): Há somente um indivíduo no departamento, excluindo a possibilidade de autocitação. (F/I): Relação Formal/Informal

(I): Relação exclusivamente informal 


\begin{tabular}{|c|c|c|c|c|c|c|c|c|c|c|c|c|c|c|c|c|}
\hline \multirow{18}{*}{ 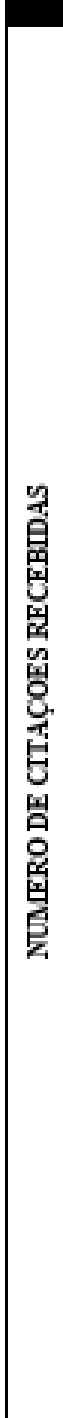 } & \multicolumn{16}{|c|}{ NUMERO DE RELACOES ESTABELECIDAS } \\
\hline & & DIREÇAO & COORD. & DOCENTE & SECRET. & CONTAB. & FINANC. & GCRED & MANUT & LIMP & LAB & CPD & MMIEIOS & MONIT & BIBLIO & TOTAL \\
\hline & DIREÇAO & $\mathrm{F} / \mathrm{I}=2$ & $F / I=3$ & $\mathrm{I}=15$ & $F /=1$ & 0 & 0 & 0 & 0 & 0 & $F /=1$ & $\mathrm{~F} I=2$ & 0 & 0 & 0 & $\begin{array}{l}F /=9 \\
I=15\end{array}$ \\
\hline & COORD. & $\mathrm{F} I=6$ & $F / I=1$ & $\begin{array}{c}\mathrm{F} / \mathrm{I}=28 \\
\mathrm{I}=2\end{array}$ & $\mathrm{~F} / \mathrm{I}=1$ & 0 & 0 & 0 & 0 & $\begin{array}{c}\mathrm{F} I=1 \\
\mathrm{I}=1\end{array}$ & $\mathrm{~F} I=1$ & $\mathrm{I}=1$ & $\mathrm{~F} / \mathrm{I}=2$ & $\mathrm{~F} I=1$ & 0 & $\begin{aligned} \mathrm{F} / \mathrm{I} & =41 \\
\mathrm{I} & =4\end{aligned}$ \\
\hline & DOCENTE & $I=11$ & $F / I=4$ & $F / I=47$ & 0 & 0 & 0 & 0 & 0 & $\mathrm{I}=2$ & 0 & 0 & 0 & 0 & 0 & $\begin{array}{c}F /=51 \\
I=13\end{array}$ \\
\hline & SECRET. & $\mathrm{F} / \mathrm{I}=4$ & $\mathrm{~F} / \mathrm{I}=2$ & $\begin{array}{c}F /=? \\
I=3\end{array}$ & $\mathrm{~F} / \mathrm{I}=3$ & 0 & $F /=1$ & $F / I=1$ & $F /=1$ & 0 & 0 & $\begin{array}{c}\mathrm{FI}=1 \\
\mathrm{I}=2\end{array}$ & 0 & 0 & $\mathrm{~F} / \mathrm{I}=1$ & $\begin{array}{c}\mathrm{F} / \mathrm{I}=21 \\
\mathrm{I}=5\end{array}$ \\
\hline & CONTAB & $\mathrm{F} / \mathrm{I}=1$ & 0 & 0 & 0 & $F /=4$ & 0 & $F /=1$ & 0 & 0 & 0 & 0 & 0 & 0 & 0 & $\mathrm{~F} I=6$ \\
\hline & FINANC. & $\mathrm{F} I=2$ & 0 & 0 & $\mathrm{~F} / \mathrm{I}=1$ & $\mathrm{~F} / \mathrm{I}=1$ & 0 & $\mathrm{~F} / \mathrm{I}=1$ & 0 & 0 & 0 & 0 & 0 & 0 & $\mathrm{~F} I=1$ & $\mathrm{~F} / \mathrm{I}=6$ \\
\hline & GCREDD & 0 & 0 & 0 & $\mathrm{I}=1$ & $F / I=1$ & $F /=1$ & * & 0 & 0 & 0 & 0 & 0 & 0 & 0 & $\begin{array}{c}\mathrm{FI}=2 \\
\mathrm{I}=1\end{array}$ \\
\hline & MANUT & $\begin{array}{c}\mathrm{F} I=1 \\
\mathrm{I}=1\end{array}$ & 0 & 0 & 0 & 0 & 0 & 0 & $\mathrm{~F} / \mathrm{I}=7$ & $\begin{array}{c}\mathrm{FI}=1 \\
\mathrm{I}=1\end{array}$ & $F /=1$ & 0 & 0 & 0 & 0 & $\begin{array}{c}\mathrm{F} / \mathrm{I}=10 \\
\mathrm{I}=2\end{array}$ \\
\hline & LIMP & $\mathrm{F} I=1$ & 0 & $I=3$ & 0 & 0 & 0 & 0 & $\mathrm{I}=1$ & $\mathrm{FI}=$ ? & 0 & 0 & 0 & 0 & $\mathrm{I}=2$ & $\begin{array}{c}\mathrm{F} I=8 \\
\mathrm{I}=6\end{array}$ \\
\hline & $L A B$ & 0 & 0 & $\begin{array}{c}F / I=3 \\
I=4\end{array}$ & 0 & 0 & 0 & 0 & $F /=1$ & $\mathrm{FI}=1$ & * & 0 & 0 & $\mathrm{~F} / \mathrm{I}=1$ & 0 & $\begin{array}{c}F I=6 \\
I=4\end{array}$ \\
\hline & CPD & 0 & 0 & 0 & $F /=1$ & 0 & 0 & 0 & 0 & 0 & 0 & $F /=3$ & $F / I=1$ & 0 & 0 & $F /=5$ \\
\hline & MLIEIOS & 0 & 0 & 0 & 0 & 0 & 0 & 0 & 0 & 0 & 0 & 0 & $F / I=2$ & 0 & 0 & $F /=2$ \\
\hline & MONIT & 0 & 0 & 0 & 0 & 0 & 0 & 0 & 0 & 0 & 0 & 0 & 0 & * & 0 & 0 \\
\hline & BIBLIO & 0 & 0 & 0 & 0 & 0 & 0 & 0 & 0 & 0 & 0 & 0 & 0 & 0 & * & 0 \\
\hline & \multirow{2}{*}{ TOTAL } & $\mathrm{F} / \mathrm{I}=17$ & \multirow{2}{*}{$F / I=10$} & $F / I=85$ & $\mathrm{~F} / \mathrm{I}=\mathrm{7}$ & \multirow{2}{*}{$F / 1=6$} & \multirow{2}{*}{$\mathrm{F} / \mathrm{I}=2$} & \multirow{2}{*}{$\mathrm{F} / \mathrm{I}=3$} & $\mathrm{~B} / \mathrm{I}=9$ & $F /=10$ & \multirow{2}{*}{$\mathrm{F} / \mathrm{I}=3$} & $\mathrm{~F} I=6$ & \multirow{2}{*}{$\mathrm{F} / \mathrm{I}=5$} & \multirow{2}{*}{$\mathrm{F} I=2$} & $\mathrm{~F} I=2$ & $F / I=167$ \\
\hline & & $\mathrm{I}=12$ & & $\mathrm{I}=27$ & $\mathrm{I}=1$ & & & & $\mathrm{I}=1$ & $I=4$ & & & & & $\mathrm{I}=2$ & $\mathrm{I}=50$ \\
\hline
\end{tabular}

Figura 7: RSIC por departamento - Escola Privada. Fonte: Dados da pesquisa $\left.{ }^{*}\right)$ : Há somente um indivíduo no departamento, excluindo a possibilidade de autocitação. (F/I): Relação Formal/Informal 


\subsection{Motivos da formação}

Com o intuito de descobrir os motivos que levam a formação dos laços, para a terceira etapa do estudo, foi realizada a entrevista com todos os respondentes das escolas, baseadas em Sozen (2012). De acordo com o Quadro 6, a Escola Privada demonstrou maior grau de dependência entre os funcionários indicados nas Redes, enquanto que a Escola Pública apresentou menores frequências, ou seja, os colaboradores consideram-se independentes para executar suas atividades e tomar as decisões.

Quando relacionado aos motivos dos laços formados, os colaboradores de ambas as escolas mencionaram tanto aspectos formais quanto características pessoais do indivíduo citado. Destacam-se as consequências de um não relacionamento com determinada pessoa citada na Escola Pública, alegando menores efeitos, justificados pelo desempenho similar, existência de outros relacionamentos, relações externas e concurso público. Já os entrevistados da Escola Privada alegam a presença de influências negativas em termos de desempenho, vida pessoal, função, informações, saída, apoio, clima organizacional, trabalho em equipe, emprego e projetos.

Quadro 6: Comparações entre Escola Pública e Privada - motivos.

\begin{tabular}{|c|c|c|}
\hline & ESCOLA PÚBLICA & ESCOLA PRIVADA \\
\hline $\begin{array}{l}\text { Dependência } \\
\text { nas tarefas }\end{array}$ & $\begin{array}{l}\text { - Não (84) } \\
\text { - Sim (42) } \\
\text { - Indiretamente (24) }\end{array}$ & $\begin{array}{l}\text { - Sim (74) } \\
\text { - Não (53) } \\
\text { - Indiretamente (11) }\end{array}$ \\
\hline Motivos & $\begin{array}{l}\text { Função, proximidade física, tempo de } \\
\text { relacionamento, amizade, qualidades } \\
\text { profissionais, confiança, prestatividade, } \\
\text { conhecimento, apoio pessoal, afinidades, } \\
\text { parentesco e religião. }\end{array}$ & $\begin{array}{l}\text { Função, tempo de serviço, proximidade física, } \\
\text { trabalho em outra escola, qualidades pessoais, } \\
\text { qualidades profissionais, confiança, amizade, } \\
\text { apoio, informação e conhecimento, experiência, } \\
\text { afinidades e parentesco. }\end{array}$ \\
\hline Consequências & $\begin{array}{l}\text { - Não (99)= Desempenho, outros } \\
\text { relacionamentos, relação externa e Concurso. } \\
\text { - Sim (61)= Trabalho em equipe, amizade, clima } \\
\text { organizacional, função, isolamento, apoio, } \\
\text { informações, projetos e saída }\end{array}$ & $\begin{array}{l}\text { - Sim }(98)=\text { Desempenho, vida pessoal, função, } \\
\text { informações, saída, apoio, clima organizacional, } \\
\text { trabalho em equipe, emprego e projetos. } \\
\text { - Não (30)= Desempenho e outros } \\
\text { relacionamentos }\end{array}$ \\
\hline
\end{tabular}

Fonte: Elaborado pelos autores.

Após descobrir alguns condicionantes que levaram todos os colaboradores citar determinada pessoa, a última etapa do estudo consiste em verificar os motivos pelos quais os atores centrais acreditam serem os mais citados nas redes. O Quadro 7 exibe as razões e número de citações recebidas em cada rede seguindo a sequência da Escola Pública e posteriormente, no Quadro 8, na Escola Privada. 
Quadro 7: Motivos de acordo com os atores centrais - Escola Pública.

\begin{tabular}{|c|c|c|c|c|}
\hline Ator & RSI & RSA & RSC & Motivos \\
\hline $\begin{array}{c}\text { Cravo } \\
\text { (Secretaria) }\end{array}$ & $\begin{array}{c}X \\
30\end{array}$ & $\begin{array}{c}X \\
14\end{array}$ & $\begin{array}{c}X \\
18\end{array}$ & $\begin{array}{l}\text { Por causa do relacionamento que eu tenho com eles, a segurança, a } \\
\text { responsabilidade que eu procuro ter com a minha função. E a confiança e o outro } \\
\text { lado que tudo na vida tem um propósito, então eu sempre procuro orientá-los, não } \\
\text { somente dentro do ambiente de trabalho, mas nos pessoais, eu procuro conduzi-los } \\
\text { e orientá-los. }\end{array}$ \\
\hline $\begin{array}{l}\text { Rosa } \\
\text { (Direção) }\end{array}$ & $\begin{array}{c}X \\
29\end{array}$ & - & $\begin{array}{c}X \\
10\end{array}$ & $\begin{array}{c}\text { Eu senti diferença quando eu passei de professora para diretora. Antes eu era } \\
\text { colega e agora chefe, mas por questões hierárquicas mesmo. Mas os colegas que } \\
\text { eram mais próximos continuaram próximos, e aqueles que não tinham muito } \\
\text { contato, por questões do período, eu vi essa diferença. Mas eu acredito que o } \\
\text { motivo por eu ter sido citada com certeza foi por causa da direção. }\end{array}$ \\
\hline $\begin{array}{l}\text { Amarílis } \\
\text { (Direção) }\end{array}$ & $\begin{array}{c}X \\
23\end{array}$ & $\begin{array}{c}X \\
12\end{array}$ & $\begin{array}{c}X \\
10\end{array}$ & $\begin{array}{c}\text { Eu quero acreditar que a minha função não tenha influenciado em nada. Acredito } \\
\text { que se eu fosse ainda professora eu teria essa quantidade de citações, porque } \\
\text { como eu falei se eles estão olhando na parte da responsabilidade, na simpatia, de } \\
\text { estar de bem com os relacionamentos, eu não quero acreditar que seja por causa } \\
\text { do cargo, até porque aquelas pessoas que eu tinha contato eu ainda mantenho, e } \\
\text { com aquelas que eu não me relacionava eu to tentando me aproximar até para } \\
\text { tentar ajudando. }\end{array}$ \\
\hline $\begin{array}{c}\text { Azálea } \\
\text { (Coordenação) }\end{array}$ & $\begin{array}{c}X \\
22\end{array}$ & - & - & $\begin{array}{c}\text { Como o cargo que eu ocupo é de liderança é normal que os colegas citem o meu } \\
\text { nome na rede de informação. Também porque procuro passar e organizar o } \\
\text { máximo a escola para facilitar o meu próprio trabalho. }\end{array}$ \\
\hline $\begin{array}{c}\text { Begonia } \\
\text { (Coordenação) }\end{array}$ & $\begin{array}{c}X \\
13\end{array}$ & - & - & Acho que foi por causa da minha função sim. \\
\hline $\begin{array}{c}\text { Lírio } \\
\text { (Administrativo) } \\
\end{array}$ & - & $\begin{array}{c}X \\
10 \\
\end{array}$ & - & $\begin{array}{r}\text { Acho que é porque eu sou humilde e } \\
\text { problema }\end{array}$ \\
\hline $\begin{array}{l}\text { Angélica } \\
\text { (Cozinha) }\end{array}$ & - & $\begin{array}{l}X \\
9\end{array}$ & - & $\begin{array}{l}\text { A função ajudou a quantidade de nomes, eu também sou a mais antiga daqui. } \\
\text { Quando todo mundo entrou aqui eu já estava e fui criando amizades. }\end{array}$ \\
\hline $\begin{array}{c}\text { Dália } \\
\text { (Corpo } \\
\text { Docente) }\end{array}$ & - & $\begin{array}{l}X \\
10\end{array}$ & $\begin{array}{l}X \\
6\end{array}$ & $\begin{array}{l}\text { Eu me considero muito brincalhona. No ambiente de trabalho, eu foco muito a } \\
\text { questão da parte humana, a gente se envolve muito com o nosso trabalho. E às } \\
\text { vezes o colega com um olhar, não amanhece e a gente acaba indo perguntar, ver o } \\
\text { que tá acontecendo. Eu sempre procuro fazer isso. Acredito que o fato de eu ter } \\
\text { passado pela vice direção e coordenação não tenha influenciado a votação, porque } \\
\text { isso já faz muito tempo. Acho que a função atual não influenciou. }\end{array}$ \\
\hline $\begin{array}{c}\text { Flor de lis } \\
\text { (Corpo } \\
\text { Docente) }\end{array}$ & - & - & $\begin{array}{l}X \\
6\end{array}$ & $\begin{array}{c}\text { Talvez pelo tempo de trabalho criou-se laços de amizade e de confiança conforme } \\
\text { a gente foi se conhecendo, mas eu acredito que seja mais nos termos de receber e } \\
\text { de falar, porque eu não sou assim uma pessoa estressada, procuro ser uma pessoa } \\
\text { bem educada, sempre manter a educação. Esse meu lado foi que favoreceu essa } \\
\text { votação. }\end{array}$ \\
\hline
\end{tabular}

Fonte: Dados da pesquisa.

Destaca-se o papel dos atores centrais Cravo e Amarílis presentes nas três redes. Sozen (2012) afirma que aqueles que ocupam posições centrais na organização tem maior frequência de interações por serem responsáveis pela coordenação de outros setores, e também por mostrarem qualificação e alta preferência para realização de atividades estão propensos a ganhar posições centrais nas redes. Assim como ilustrado no Quadro 7, nota-se que de acordo com as percepções de cada ator central, apesar de alguns mencionarem questões formais, outros alegam suas qualidades pessoais e tempo de serviço como motivos que fizeram seus colegas citarem-nos.

Semelhante à Escola Pública, os membros da Escola Privada também mencionam aspectos voltados ao cargo e às qualidades, como ilustra o Quadro 8. No entanto, destacam também relações com o tempo de serviço, experiências, exemplos de vida, empatia, disponibilidade, entre outros. 
Quadro 8: Motivos de acordo com os atores centrais - Escola Privada

\begin{tabular}{|c|c|c|c|c|}
\hline Ator & RSII & RSIA & RSC & Motivos \\
\hline $\begin{array}{c}\text { Jequitibá } \\
\text { (Direção) }\end{array}$ & $\begin{array}{c}X \\
25\end{array}$ & - & $\begin{array}{c}X \\
14\end{array}$ & $\begin{array}{c}\text { "Eu sinto que eles acreditam na minha proposta pedagógica, é porque eu não me } \\
\text { fechei na função de diretora, porque eu vou sempre estudar e até hoje eu estudo. } \\
\text { Eu sinto que eu sou um exemplo para eles. Eu fui a primeira a fazer mestrado aqui, } \\
\text { eu incentivei vários. Então eu vejo que eles me veem como uma referência na } \\
\text { educação. Mas eu também acredito que com certeza foi por causa da minha função } \\
\text { que eles me citaram, mas não vejo isso como um problema, vejo como uma } \\
\text { aceitação do cargo, porque eles poderiam omitir a direção". }\end{array}$ \\
\hline $\begin{array}{c}\text { Eucalipto } \\
\text { (Direção) }\end{array}$ & $\begin{array}{c}X \\
20\end{array}$ & - & $\begin{array}{c}X \\
10\end{array}$ & $\begin{array}{c}\text { "Eu procuro ter uma relação de confiança, procurando cobrar com bastante } \\
\text { intensidade as funções de cada colaborador, mas procurando ajuda-los a } \\
\text { desempenhar a tarefa funcionalmente e ajudando na sua vida particular, } \\
\text { procurando saber as suas necessidades e ajudando dentro as nossas } \\
\text { possibilidades.. mas eu acredito que é devido ao fato de eu ser dono da escola que } \\
\text { me citaram, talvez se eu exercesse outra função também seria citado, mas um } \\
\text { pouco menos". }\end{array}$ \\
\hline $\begin{array}{c}\text { Ipê } \\
\text { (Coordenação) }\end{array}$ & $\begin{array}{c}X \\
39\end{array}$ & $\begin{array}{c}X \\
22\end{array}$ & $\begin{array}{c}X \\
25\end{array}$ & $\begin{array}{c}\text { “Eu não sei te dizer o porquê, se é pelo fato de eu ter mudado várias vezes de } \\
\text { função, por eu ser antiga aqui na escola. Mas uma coisa eu te falo, eu trabalho com } \\
\text { a teoria do amor, que faz a gente trabalhar em equipe, e conhecer também a } \\
\text { escola. Eu conheço cada pedacinho da escola, cada parte da escola eu conheço. } \\
\text { Mas com certeza quem citou foi o pessoal da manhã. Eu tenho um relacionamento } \\
\text { muito bom com todos". }\end{array}$ \\
\hline$\underset{\text { (Coordenação) }}{\text { Alecrim }}$ & $\begin{array}{c}X \\
24\end{array}$ & - & - & $\begin{array}{c}\text { "Eu acho que eu sou uma pessoa muito amiga, eu tento sempre me colocar no } \\
\text { lugar do outro. Eu escuto muito. E eu tento ser uma líder e é difícil ser, é fácil você } \\
\text { ter o cargo, é mais difícil você ser líder, você conquistar por aquilo que você é. E eu } \\
\text { acho que a minha função influenciou sim a citação do meu nome, porque o } \\
\text { coordenador é o ponto chave da direção, talvez se eu fosse de outro setor não seria } \\
\text { tão citada porque eu to todo dia aqui presente com o professor, então eu acho que } \\
\text { a coordenação é um ponto que influencia sim". }\end{array}$ \\
\hline $\begin{array}{c}\text { Jatobá } \\
\text { (Coordenaçãa) }\end{array}$ & $\begin{array}{c}X \\
23\end{array}$ & - & $\begin{array}{c}X \\
11\end{array}$ & $\begin{array}{r}\text { "A gente sempre ajuda, conversa, dá a mão, } \\
\text { divergência a gente conversa. E a gente acabc } \\
20 \text { anos, não tem como eu não ter } 4 \\
\end{array}$ \\
\hline $\begin{array}{l}\text { Pinheiro } \\
\text { (Secretaria) }\end{array}$ & - & $\begin{array}{c}X \\
22\end{array}$ & - & $\begin{array}{c}\text { "Sou super disponível e prestativa, mas eu acredito que a minha função e o tempo } \\
\text { de serviço ajudaram muito também na citação, porque na escola o pessoal tem } \\
\text { mais contato com a secretaria diretamente, mas além de você ser secretária você } \\
\text { procura ser amiga, perguntar se está bem hoje. Não tem como ser somente colega } \\
\text { de serviço". }\end{array}$ \\
\hline $\begin{array}{l}\text { Mogno } \\
\text { (Corpo } \\
\text { Docente) }\end{array}$ & - & $\begin{array}{c}X \\
17\end{array}$ & - & $\begin{array}{c}\text { "Eu tenho cargos de liderança em vários projetos aqui na escola, e isso agrega } \\
\text { pessoas da escola. Isso é uma coisa que ajuda. Mas acredito que seja também } \\
\text { pela disponibilidade, eu sou uma pessoa de acesso fácil e eu passo muito tempo } \\
\text { dentro da escola. E como eu to aqui há } 25 \text { anos, ajudou muito a entender como os } \\
\text { patrões pensam, já tenho um jeito de saber como proceder, de conhecer as regras } \\
\text { da escola, as normas, de conhecer a coordenação e direção". }\end{array}$ \\
\hline $\begin{array}{c}\text { Pau-brasil } \\
\text { (Corpo } \\
\text { Docente) } \\
\end{array}$ & - & $\begin{array}{l}X \\
14\end{array}$ & - & $\begin{array}{c}\text { "Eu faço muitas brincadeiras, mas na hora de falar sério eu falo, eu sempre estou } \\
\text { aberto. Acredito que não tem nada a ver com a minha função, eu sempre procuro } \\
\text { ouvir as pessoas, ser amigo". }\end{array}$ \\
\hline $\begin{array}{c}\text { Cedro } \\
\text { (Laboratório) }\end{array}$ & - & $\begin{array}{c}X \\
14\end{array}$ & $\begin{array}{c}X \\
10\end{array}$ & $\begin{array}{c}\text { "Deve ser a palhaçada que eu faço. Eu brinco com todo mundo. Eu aceito também } \\
\text { que eles façam isso comigo. Eu acho que é isso, o meu humor que deve ter } \\
\text { conquistado. Mas quando eles me pedem alguma coisa, eu procuro atender. Se } \\
\text { não estiver ao meu alcance eu corro atrás. Vou atrás da pessoa que pode atender. } \\
\text { Eu faço o que eu puder. Desde que eu esteja disponível". }\end{array}$ \\
\hline
\end{tabular}

Fonte: Dados da pesquisa.

Destacam-se que a Coordenadora Ipê é identificada como atriz central em todas as redes (recebendo maior quantidade de citação nas três redes) e que a maioria é caracterizada por funções de gerência e direção, isto é, além do cargo dar o direito de usar o poder da influência nas relações formais, eles possuem a habilidade em conseguir influenciar seus subordinados informalmente. 


\section{DISCUSSÃO DOS RESULTADOS}

A organização pública opera de maneira diferente de uma organização privada, provocando atitudes e comportamentos distintos em seus funcionários (BAARSPULL, 2009). Os órgãos públicos enfrentam uma série de partes interessadas, cada um dos quais coloca exigências e restrições em gerentes. Metcalfe (1993) citado por Boyne (2002) argumenta que o governo trabalha através de redes de organizações interdependentes e não através de organizações independentes que visam alcançar seus próprios objetivos.

Da mesma forma, o setor privado é capaz de criar estratégias de redes intraorganizacionais de modo a conseguir controlar rigidamente a estrutura hierárquica e consequentemente a conduta de seus subordinados. Contrário às organizações públicas em que os gestores precisam lidar com as regras e burocracia, e sem a liberdade de liderar seus dependentes em função das normas de contratação, demissão e promoção inflexíveis (WEINBERG, 1983 apud BOYNE, 2002).

Considerando esses fatores e os resultados alcançados, o presente estudo identificou algumas diferenças nas relações na escola pública e na privada. Foram entrevistados 66 indivíduos na Escola Pública e 73 na Escola Privada, o que permitiu a variação do número de relações informais. Em razão dos graus de subordinação, chefia e critérios funcionais, foram estabelecidos os relacionamentos formais existentes em ambas as escolas conforme observações e entrevistas.

Destaca-se que Redes Sociais Informais de Informação (RSII) e de Confiança (RSIC) foram mais citadas no setor privado, pois apresentaram densidade superior ao setor público. Afirma-se que o fato pode estar relacionado às reuniões semanais, tempo de serviço, vários colaboradores possuem mais de um chefe, e com exceção do Corpo Docente, todos os outros departamentos trabalham em período integral. Evidenciase também a Rede Social Informal de Amizade (RSIA) ser maior na Escola Pública, uma vez que a sua densidade $(7,46 \%)$ foi mais excedente do que a privada $(6,96 \%)$. Associa-se ao motivo da ausência de pressões competitivas, tanto em nível organizacional como individual, porque os gestores públicos freqüentemente desfrutam de uma posição dominante no mercado (BOYNE, 2002) e também seus colaboradores apresentam estabilidade na função (BERGUE, 2005).

No estudo de Cross e Parker (2004) foram citadas seis dimensões que podem afetar os relacionamentos entre os envolvidos: a Posição Hierárquica Relativa, Posição Organizacional Relativa, Proximidade Física, Estrutura de Interações, Tempo investido na manutenção de relacionamentos e Tempo de Conhecimento. Na presente pesquisa, os resultados das Redes Sociais de Informação das escolas Pública e Privada corroboram com todas as dimensões. Já nas Redes Sociais de Amizade das duas escolas não foi a posição hierárquica que explicou a formação da rede de amizade, mas sim a posição organizacional, proximidade física, estrutura de interações e o tempo investido na manutenção de relacionamentos, fato que pode ser exemplificado pelas relações permaneceram com maior frequência no mesmo departamento. Por fim, nas Redes Sociais de Confiança das duas escolas pesquisadas, a posição hierárquica explicou diretamente a formação dos laços de confiança. No entanto, quando foi realizada a análise dos motivos da formação de laços, os colaboradores de ambas as escolas citaram tanto aspectos formais quanto características pessoais do indivíduo citado.

Desse modo, o presente artigo propõe a sétima dimensão que consiste nas "Qualidades pessoais e profissionais" englobando a amizade, confiança, disponibilidade, comprometimento, agilidade, grau de 
parentesco, humor, afinidades entre outros que explicam diretamente a formação do laço a priori ou a posteriori, bem como a centralidade dos atores. Dessa forma, de acordo com os resultados da pesquisa, não são somente fatores associados ao contexto estrutural, seja em organização pública ou privada, que faz com que os envolvidos se relacionem, mas também as virtudes pessoais e profissionais que facilitam o contato e a aproximação entre os mesmos, independentemente se a rede for de informação, amizade ou confiança. As qualidades dos indivíduos os tornam mais centrais e intermediários em suas redes de relacionamentos, e permitem que sejam mais coesos com o grupo, podendo assim fomentar contatos que promovam mais acessos à informação, ideias, inovação; como também sentimentos de união, solidariedade e empatia.

\section{CONSIDERAÇÕES FINAIS}

O presente estudo de casos múltiplos teve como objetivo verificar os condicionantes que influenciam as redes sociais de informação, amizade e confiança em duas organizações, sendo uma pública e outra privada. Os objetos para a pesquisa foram duas escolas (uma pública e outra privada) localizadas na cidade de Ponta Porã, MS.

Para o desenvolvimento do presente artigo, foi aplicado um questionário baseado nos estudos de Kuipers (1999) e Silva (2003) para o mapeamento das Redes Sociais de Informação, Amizade e Confiança a todos os colaboradores da Escola Pública (66 indivíduos) e Privada (73 indivíduos), cuja identificação dos atores era codificada por tipos de árvores e flores.

A fim de compreender os motivos dos laços, os entrevistados foram solicitados a justificar as razões que os levavam a citar determinada pessoa. Posteriormente, descobriu-se os cinco atores principais das Redes de Informação, Amizade e Confiança e realizou-se uma entrevista com esses indivíduos com o objetivo de descobrir os motivos que eles avaliam ser a causa da quantidade de indicações recebidas. O roteiro préestabelecido de entrevista teve como finalidade diagnosticar se as relações confirmam as seis dimensões de Cross e Parker (2004). Tanto na Escola Pública como na Escola Privada, nove atores centrais responderam o roteiro.

Como resultados, As Redes Sociais de Informação e Confiança foram maiores na Escola Privada do que na Pública, e em contrapartida, a Rede Social de Amizade foi maior na Pública. Também se destaca que apesar da maioria dos relacionamentos da Escola Privada ser estabelecida mediante estrutura hierárquica, sendo confirmada a dependência nas atividades nas falas dos entrevistados; e que na Escola Pública não houve a formação de tantos grupos coesos como na Escola Privada. Quando relacionado aos motivos dos laços formados, os colaboradores de ambas as escolas mencionaram tanto aspectos formais quanto características pessoais do indivíduo citado, e que em alguns casos, quando o ator mencionado possui cargo de liderança, além de ter o direito em usar o poder, também tem a habilidade em saber utilizá-lo.

Recomenda-se que ambas as escolas promovam estratégias e ações para melhorar a coesão das redes informais e formais entre os departamentos, de modo a aproveitar o verdadeiro potencial das relações existentes e ampliar os laços com aqueles atores que encontraram-se isolados nas três redes. Os vínculos podem ocorrer de forma diferente e variada, no entanto, as vantagens somente serão alcançadas quando houver a oportunidade de transação da sub-rede dentro da estrutura social, isto é, a frequência crescente dos 
contatos pode transformar as relações de trabalho em relações sociais proporcionando vários benefícios para os indivíduos como para a organização (RÉGIS, 2005; SOZEN, 2012).

Apesar de ser um estudo de múltiplos casos, as limitações englobam a delimitação apenas de redes intraorganizacionais e pelo fato da pesquisa ser em um corte transversal, ou seja, os resultados não podem ser generalizáveis, pois os sentimentos e os comportamentos das pessoas podem se modificados ao longo do tempo e também por não ser possível definir o resultado como sendo o padrão para todas as organizações públicas e privadas. Embora citadas alguns entraves, considera-se que o estudo contribuiu para ampliação de pesquisas sobre os fatores condicionantes que levam à formação de redes sociais de informação, amizade e confiança em escolas pública e privada. O presente artigo não tem por finalidade esgotar outras possibilidades de análises, mas, instigar outros estudos que acrescentem conhecimento maiores sobre 0 tema.

\section{REFERÊNCIAS}

BAARSPUL, H. C. Do Employees Behave Differently in Public- vs. Private-Sector Organizations? A State-of-the-Art Review. Department of Information Systems and Change Management (ISCM) School of ManagemenT, 2009.

BARDIN, L. Análise de conteúdo. Lisboa: Edições 70, 2006.BERGUE, S. T. Gestão de pessoas em organizações públicas: uma abordagem orientada para a Administração Pública Municipal. Caxias do Sul: Educs, 2005.

BERGUE, S. T. Gestão de pessoas em organizações públicas: uma abordagem orientada para a Administração Pública Municipal. Caxias do Sul: Educs, 2005.

BORGATTI, S. P. et al. Network Analysis in the Social Sciences. Science, v. 323, n. 5.916, p. 892-895, 2009.

BOYNE, G. A. Public and private management: what's the difference? Journal of Management Studies. v. 39, n. 1, January, 2002.

BREI, V. A.; ROSSI, C. A. V. Confiança, Valor Percebido e Lealdade em Trocas Relacionais de Serviço: Um Estudo com Usuários de Internet Banking no Brasil. Revista de Administração Contemporânea, v. 9, n. 2, p. 145-168, abr./jun. 2005.

CROSS, R.; PARKER, A. The hidden power of social networks - understanding how work really gets done in organizations. 1 ed. Boston, Massachusetts: Harvard Business School Press, 2004.

DOURADO, L. F. Políticas e gestão da educação básica no Brasil: limites e perspectivas. Educação e Sociedade, Campinas, v. 28, n. 100 - Especial, p. 921-946, out/ 2007.

GIL, A. C. Como elaborar projetos de pesquisa. 4. ed. São Paulo: Atlas, 2002.

GORDON, S. R. The role of interpersonal trust and vigilance in the process of entrepreneurial opportunity recognition using social networks. In Gillin, L. Murray (Ed.) Regional Frontiers of Entrepreneurship Research, Swinburne University of Technology, Melbourne, Unitec, Auckland, pp. 42-61, 2006

GRANOVETTER, M. The Strength of weak ties. American Journal of Sociology. v. 78, p. 1360-1380, 1973.

HARTMAN, R. L.; JOHNSON, J. D. Formal and informal group communication structures: an examination of their relationship to role ambiguity. Social Networks, v. 12, p. 127-151, 1990.

KRACKHARDT, D.; HANSON, J. R. Informal Networks: the company behind the chart. Havard Business Review, Boston, Mass., v. 71, n. 4, p. 104-111, Jul./Ago, 1993.

KUIPERS, K. J. Formal and informal networks in the workplace. Dissertation (Doctor of Philosophy). Stanford University, California, USA, 1999.

LAGO JUNIOR, M. W. Redes sociais informais intraorganizacionais e os processos e mudanças organizacionais: estudo em uma empresa de tecnologia da informação. 2005. 250f. Dissertação (Mestrado Profissional em Administração). Universidade Federal da Bahia, Salvador, BA, 2005.

MACAMBIRA, M. O. Comprometimento organizacional e Redes Sociais Informais: a estrutura das relações interpessoais e o vínculo com a organização. 2009. 118f. Dissertação (Mestrado em Psicologia). Universidade Federal da Bahia. Salvador, BA, 2009.

MARTELETO, M. R. Análise de Redes Sociais: Aplicação nos estudos de transferência de informação. Ciência da Informação: Brasília, v. 30, n. 1, p. 71-81, jan./abr. 2001. 
MARTINS, J. P. Administração escolar: uma abordagem crítica do processo administrativo em educação. 2. ed. São Paulo: Atlas, 1999.

MCGRAUTH, C.; KRACKHARDT, D. Network Conditions for Organizational Change. Journal of Applied Behavioral Science, v. 39, n. 3, p. 324-336, 2003.

MINICUCCI, A. Dinâmica de grupo teorias e sistemas. 4. ed. São Paulo: Atlas, 1997.

NAHAPIET, J.; GHOSHAL, S. Social Capital, Intellectual Capital, and the Organizational Advantage. The Academy of Management Review, v. 23, n. 2, p. 242-266, Apr., 1998.

NEVES, J. L. Pesquisa Qualitativa - Características, usos e possibilidades. Caderno de pesquisa em Administração, São Paulo, v. 1, n. 3, $2^{\circ}$ sem., 1996.

RANK, O. N. Formal structures and informal networks: Structural analysis in organizations. Scandinavian Journal of Management. v. 24, p. 145-161, 2008.

RÉGIS, H. P. Construção social de uma rede informal de mentoria nas incubadoras de base tecnológica do Recife. 2005. Tese (Doutorado em Administração). Universidade Federal de Pernambuco. Recife, PE, 2005.

RÉGIS, H. P.; DIAS, S. M. R. C.; BASTOS, A. V. B. Articulando Cognição, Redes e Capital Social: um estudo entre empresários participantes de incubadoras de empresas. In: Anais... XXX Encontro da Associação Nacional de PósGraduação e Pesquisa em Administração, Salvador-BA, 2006.

SCOTT, J. Social network analysis: a Handbook. London, Sage Publications, 1987.

SILVA, M. C. M. da. Redes Sociais intraorganizacionais informais e gestão: um estudos nas áreas de manutenção e operação da planta hyco-8, Camaçari, Ba. 2003. 223f. Dissertação (Mestrado em Administração). Universidade Federal da Bahia. Salvador, BA, 2003.

SOARES, L. S. O papel da Network como suporte à carreira: percepção dos gerentes da Gilbarco do Brasil S/A. 2008. 143f. Dissertação (Mestrado em Administração) Faculdade de Boa Viagem. Recife, PE, 2008.

SOUZA, D. C.; DIAS, S. M. R. C. Maestros da vida: a influência dos fenômenos de mentoria e redes sociais nos executivos de uma empresa de transportes. rPot, v. 8, n. 1, p. 25-45, jan./jun., 2008.

SOZEN, H. C. Social networks and power in organizations: A research on the roles and positions of the junior level secretaries in an organizational network. Personnel Review, v. 41, n. 4, p. $487-512,2012$.

TOMAÉL, M. I.; MARTELETO, M. R. Redes Sociais: posições dos atores no fluxo da informação. Enc. Bibli: R. Eletr. Bibliotecon. Ciência da Informação, Florianópolis, n. esp., $1^{\circ}$ sem. 2006.

YIN, R. K. Estudo de caso: planejamento e métodos. Tradução de Daniel Grassi. Porto Alegre: Bookman, 2010. 